\begin{tabular}{c} 
International Journal of Engineering \& Technology, $7(4)(2018) 2271-2290$ \\
International Journal of Engineering \& Technology \\
Website: $\begin{array}{c}\text { ww. sciencepubco.com/index.php/IJET } \\
\text { doi: } 10.14419 / \text { ijet. } 7 \text { it. } 18150 \\
\text { Research paper }\end{array}$ \\
\hline
\end{tabular}

\title{
A review on deterministic and stochastic models for electrical treeing initiation and propagation in solid insulation systems from the perspective of prediction assessment techniques
}

\author{
Balamurugan. $\mathrm{H}^{1}$, Venkatesh. $\mathrm{S}^{2 *}$ \\ ${ }^{1}$ Research Scholar, Vellore Institute of Technology, Vellore, India \\ ${ }^{2}$ Associate Professor, Vellore Institute of Technology, Vellore, India \\ *Corresponding author E-mail: venkatsri73in@gmail.com
}

\begin{abstract}
Electrical treeing is a challenging prospect related to degradation mechanism in dielectrics that eventually leads to its breakdown. Treeing propagation depends on dielectric and electrode configuration thus leading to types such as branch, filamentary, bush etc. Though researchers have attempted a gamut of studies related to treeing, it is evident that appropriate choice of prognostic model is essential for prediction of ageing of insulation that emulate features such as dendrite length, channel width, space charge etc. Although studies related to treeing modeling have taken up depictions such as Diffusion Limited Aggregation, Field Limiting Space Charge etc. to obtain estimates of electric potential based on boundary value equations (Laplace and Poisson) utilizing tools such as Fractal Analysis, Cellular Automata etc., challenges such as space charge, inhomogeneity factor etc. continue to confront researchers. This research gives a detailed insight into a wide spectrum of studies related to treeing and ageing prediction assessment of insulation based on physical, electrical, numerical and analytical models developed thus far. This study also summarizes succinctly, the merits and limitations in each method and avenues for improvement. Finally, this research gives clues into important future opportunities related to methodologies for development pertaining to treeing prediction and ageing assessment.
\end{abstract}

Keywords: Cellular Automata (CA); Discharge Avalanche Model (DAM); Diffusion Limited Aggregation (DLA); Partial Discharge (PD); Self-Consistent Model (SCM).

\section{Introduction}

Though the origin of discerning electrical treeing can be traced back to 1777 when the discrimination of treeing was identified by the terminology called 'Lichtenberg Figures' [1] subsequently followed by several research activities taken up by the researchers in the early 1950s', a major step towards understanding the breakdown in solid dielectrics related to electrical tree formation and growth was initiated during the International Conference on Conduction and Breakdown in Solid Dielectrics in 1983. The major highlight of the findings as a part of the conference was the need towards understanding of the nature of electrical field in low density regions of a dielectric system. This in turn necessitates a clear conception of the processes related to transfer of energy from the field to the solid dielectric. In this context, it is pertinent to note that several researchers have undertaken pioneering work related to postulating electrical treeing phenomenon and its growth.

Electrical treeing is fundamentally a pre-breakdown mechanism in a dielectric system whose path of growth process has structural semblance to branch-like (tree) appearance. Initiation of electrical treeing is fundamentally due to the application of high divergent electric fields (alternating, direct and impulse) which is a direct consequence of stress in dielectric material due to specific geometric attributes that simulate extremely non-uniform fields (point-plane electrodes, needle-plane electrodes, coaxial electrodes, discharges produced in cavities filled with air etc.), polarity reversal of direct current (DC) fields. It is also worth noting that treeing may or may not lead to breakdown of the dielectric. Similarly, the process of initiation and growth of electrical treeing may or may not take a long duration, since it is strongly governed by specific environmental and localized conditions such as moisture, humidity, space-charge [2], pressure and temperature inside cavities etc.

It is evident from the preceding discussion that several challenges related to replicating real-time electrical treeing initiation and growth will continue to confront the research community such as difficulties in obtaining similar test conditions (ambient temperature, humidity, moisture) in controlled laboratory environments, complexities in ensuring high degree of reliability of treeing prediction related test results due to unavoidable variations in the polymerization index of each type of insulation test object / sample, spurious discharges due to dielectric boundary or surface imperfections etc. Hence, it becomes inevitable that for correlation, cross-validation and meaningful assessment of treeing initiation and growth mechanism, prediction of electrical treeing is taken up using modeling procedures that would possibly replicate the practical aspects that govern its mechanism. Several researchers have postulated a wide range of equivalent models which are broadly classified into two major groups namely deterministic and stochastic. These models describe treeing initiation and growth based on a variety of parameters and features that characterize treeing such as tree inception voltage, tree length, role of injected 
space charge, distribution of the localized electric field, material inclusions (defects) with varying relative permittivity of dielectric materials, role of homo and hetero charges, nano-composite etc. Mathematical models that tend to replicate such electrical treeing initiation phenomenon which have been in vogue in recent years include Niemeyer's Dielectric Breakdown Model (DBM), Niemeyer -Pietronero- Wiesmann (NPW) Model, Wiesmann Zeller (WZ) Model, Diffusion Limited Aggregation Model (DLA), Discharge Avalanche Model (DAM), Self-Consistent Model (SCM), Field Limiting Space Charge (FLSC) Model, Field Driven Tree Growth (FDTG) model, Dielectric Inhomogeneity Model for Electrical Treeing (DIMET) etc. In this context several numerical and prognostic techniques have been utilized for treeing prediction process which involves exploiting iterative procedures to obtain parameters that influence the growth of electrical trees due to electric potential and electric stresses repetitively at appropriate locations of interest in a dielectric system. A few of the major techniques include Finite Difference Method (FDM), Finite Element Methods (FEM), Boundary Element Method (BEM), Charge Simulation Method (CSM) etc. In addition, prediction of tree propagation and growth has been carried out utilizing tools such as Percolation Model, Fluctuation Model, Fractal Analysis (FA), Cellular Automata (CA) etc.

The focus of this research paper is on providing a considerably comprehensive summary of the various merits and limitations of such techniques. It is also the focus of this research to explore on the recent developments in image processing and applications related to virtual imagery which may provide plausible avenues in enhancing the tree growth prediction capability in addition to providing in depth details on the electrical tree morphological patterns and role / significance of tree types in degradation process.

\section{Electrical treeing - types, properties / char- acteristics \& factors influencing the phenom- enon}

\subsection{Electrical tree types}

Over the past few decades various types of electrical tree morphological structures have been obtained and analysed by researchers. Electrical tree morphological structures are broadly classified into two major categories namely 'vented' and 'nonvented' types. Initiation and growth of discharges that lead to electrical tree at surfaces which involve abundant supply of air or water leading to cumulative bridging of the electrodes completely within a very short period are called 'vented trees'. On the other hand, propagation of tree structures that start at internal inclusions (cavities, voids, fissures etc.) in dielectric material or a foreign are categorized as 'non-vented trees'. In some rare cases these nonvented trees may grow larger as compared with the vented trees. It is evident from this discussion that electrochemical treeing (watertreeing) involves vented trees while electrical treeing relates to nonvented tree morphologies. A few types of non-vented tree morphological patterns include dendrite, branch, bush, branch-bush, fan, fibrillar, intrinsic etc., while vented tree structures comprise bow-tie, string etc. Important and interesting properties related to electrical treeing has been reported by researchers which describe on the conversion of morphological tree pattern types due to the dielectric and electrical field characteristics.

It is evinced that in the case of polymeric (polyethylene) samples of large thickness which displayed bush type tree structures, bush growth patterns may cease for a considerable time period after which it is observed that filamentary discharge patterns are initiated that sometimes cumulatively lead to small flower-like structures, the behaviour of which is not clearly comprehended. In a few cases such filamentary discharges extend into bush type patterns. It is observed that in such cases the local field essential to sustain the process would be usually larger (greater than $2.5 \mathrm{kV} / \mathrm{mm}$ to $3 \mathrm{kV} / \mathrm{mm}$ ). Such influences are created due to narrow cracks of very small radii. Another case of treeing pattern transition in morphological structure is also observed wherein the maximum field around the tree tips is less than the minimum field essential for tree extension. In specific cases of bush type trees, propagation of channels of electric tree is observed to cease. It is further witnessed that after a substantial time, discharges in the tubules of the tree channels led to conducting channels capable of supporting larger discharges. This is hypothesized due to the effect of an image charge in the other electrode which acts as a possible space charge thus possibly accelerating the propagation of bush-branch tree morphologies. A specific variant of tree morphology which is invariably due to the high and enhanced local electrical field in the close proximity of the defect / inclusion location leads to intrinsic or fibrillar type morphologies. Such types of tree patterns become extremely significant in the context of cross linked polyethylene (XLPE) cable insulation systems.

\subsection{Properties / characteristics of electrical treeing}

\subsubsection{Time for initiation and propagation}

Electrical treeing process involves two major stages namely inception and propagation. The inception stage is characterized by an initiation time which is appropriate to the nature of the applied field which is AC while in the case of DC it is related to the number of pulses. During the propagation stage, treeing develops and the damage leading to subsequent degradation of dielectric is observed in the form of very small tubules or cavities (dendrite-like structures). Another perspective related to electrical treeing characteristic in terms of time for breakdown is observed from the context of two major time durations namely channel appearance ( $\left.t_{\text {ch.a }}\right)$ and channel development $\left(t_{\text {ch.d }}\right)$. The total time taken by the breakdown channel for its first appearance is generally known as the channel appearance time ( $t_{c h . a}$ ) which relates to the beginning of treeing formation while the time taken by the channel for the growth of treeing up to another electrode is called channel development time ( $\left.t_{c h . d}\right)$ which may significantly vary in different materials based on environmental conditions such as temperature, moisture, pressure in cavity etc. Hence, the time to breakdown of the dielectric due to treeing is the sum of the appearance and development time $\left(t_{c h . d}+t_{c h . a}\right)$. It is pertinent to note that in most practical applications, $t_{c h . d} \gg t_{\text {ch.a }}$ in the case of extremely nonuniform fields while $t_{c h . d}<<t_{c h . a}$ in the case of weakly non-uniform fields.

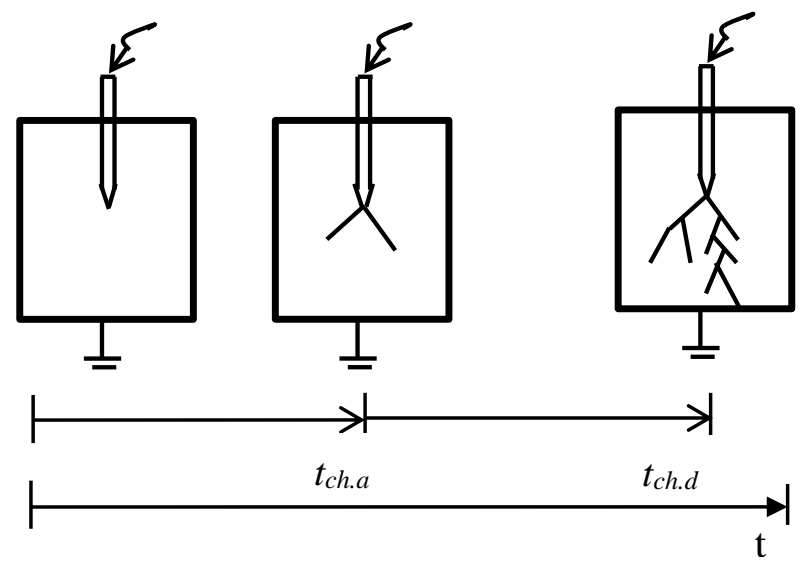

Fig. 1: Breakdown in an Extremely Non-Uniform Field $\left(t_{c h . d}>t_{\text {ch.a }}\right)$. 


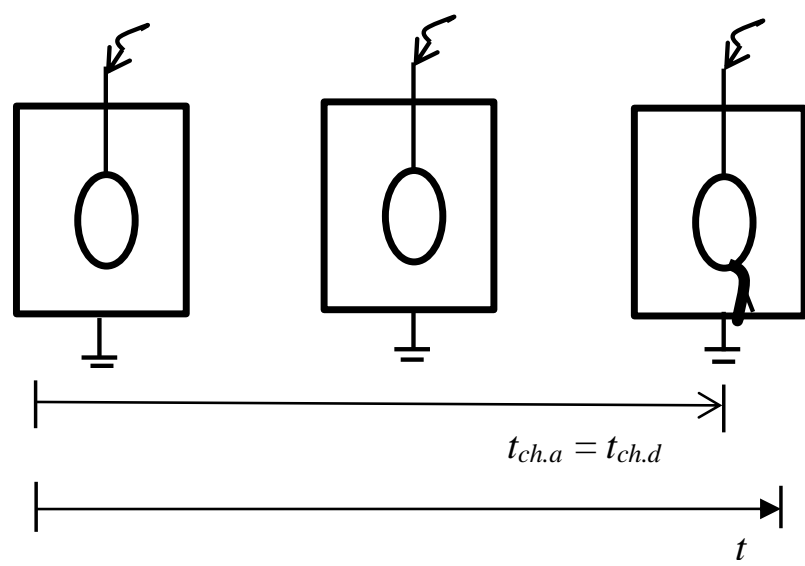

Fig. 2: Breakdown in A Weakly Non-Uniform Field ( $\left.t_{\text {ch.d }}<<t_{\text {ch.a }}\right)$.

Fig. 1 and Fig. 2 clearly point towards the effect of an electrode configuration with extremely non-uniform and weakly non-uniform fields in an electrical tree growth. In an extremely non-uniform field (a specific case of field created by the needle-plane electrode) as in Fig. 1, the electrode will take individual time delay for the appearance and development of electrical tree channel as compared with the weakly non-uniform field (as in case of field created by the sphere-plane electrode) as in Fig. 2 in which this electrical tree channel will not take any separate time delay for its appearance and development but both the processes may occur simultaneously.

\subsubsection{Partial discharge (PD) related to treeing}

It is extremely significant to note that electrical treeing is always complemented with the phenomenon of Partial Discharge (PD) [3] which may also be detected, measured and analyzed. Hence, it becomes important that the characteristics and properties of PD pulse data would inherently provide important clues into treeing related degradation mechanism. In this context, it becomes imperative to consider the phenomenon of electro-luminescence (EL) which usually precedes the commencement of PD pulses. This aspect has been observed by researchers for a variety of polymeric insulation systems such as polyethylene, epoxy resins etc.

In terms of propagation of treeing during PD, studies have revealed that for obtaining a tubule tree channel length of a minimum of 5 $10 \mu \mathrm{m}$ with a mean radius of about $1 \mu \mathrm{m}$ a pulse discharge magnitudes greater than at least $0.2 \mathrm{pC}$ is essential [4]. It is also worth mentioning that tree propagation has a significant role to play with the glass transition temperature of the dielectric. Few significant research studies indicate that in epoxy resins below its glass transition electrical treeing are conductive in nature leading to possibility of accelerated growth.

\subsubsection{Role of gas pressure}

Studies related to the influence of gas pressure and its influence in treeing propagation has been carried out by very few researchers. Studies indicate that an increase in gas pressure are directly associated with the ceasing of tree discharges though initially reduction of pressure due to gas reduction / release has been is observed. Such aspects are invariably observed significantly in bush type trees. The tendency of tubule well to act as conducting medium in glass state may be attributed to a fracture that takes place in the glass state leading to a non-plastic deformation whereby substantial number of charge transfer points are made available to enable transportation of charges during tree propagation at a rapid rate.

\subsubsection{Role of space charge}

It is worth mentioning that recently there is a renewed interest and focus on studies related to the role of space charge and its influence on tree propagation in solid dielectrics. For obtaining more realistic simulation results which match considerably with practical realtime studies due to the effect of the space-charge, several researchers like [4]-[6] have attempted solving the Laplace and Poisson's equations by utilizing a step-by-step simulation procedure to ascertain the electrical tree propagation. In few research studies carried thus far [7]-[9], fractal dimensions and analysis have been used for characterizing the electrical tree morphologies with the existence of space-charge which has been observed to and considered a significant part in the prediction of size and shape of the electrical trees. In contrast, initial research studies had been carried out by several researchers [8]-[9] to ascertain treeing initiation and propagation without the presence of space-charge though with a lesser degree of precision. Based on this discussion it is interesting to note from [6] that the presence of this space-charge leads to fewer tree branches whereas more branches may initiate without the presence of space-charge.

\subsection{Factors influencing the phenomenon}

In general, researchers have found studies and analysis related to electrical tree initiation and growth a complex and abstruse phenomena since insulating materials are influenced by several factors such as applied voltage, electrode configuration, supply frequency, morphology of the material, chemical composition, interface conditions, permittivity and conductivity of both the insulating material and tree [10], ambient temperature, condition of electric field (either uniform or non-uniform) in the dielectric and the potential distribution etc. Sometimes in the composite insulating systems, the electrical tree usually develops across the interfacial region between the two different mediums or in the overlapped areas. However, when the process of treeing is initiated and manifested in the presence of an insulating barrier, treeing always tries to propagate within the weaker medium and not through insulating barriers usually located as equipotential surfaces in the composite dielectric systems [11]. Further, generally in case of nonuniform electric field arrangement, the growth rate of electrical tree has a unique and a significant correlation with field intensity and space charges present in the dielectric. Studies and analysis in [12] reveal that development of electrical treeing after its initiation is blocked in the solid insulating materials at higher critical field when the propagation of the tree channel reaches the regions where the available electric field becomes lower than that of the critical field. Table 1 compares the characteristics and features of electrical treeing with nature of electric field stresses due to direct and alternating current as the governing factor for the analysis.

Table 1: Comparison Between the Effect of AC and DC Stresses

\begin{tabular}{lll}
\hline Characteristics & AC stresses & DC stresses \\
\hline Time for tree initiation & $\begin{array}{l}\text { Easily initiates and grows with longer length } \\
\text { due to polarization and polarity reversal. }\end{array}$ & $\begin{array}{l}\text { Initiation and growth rate is slow as compared with AC } \\
\text { under the same physical conditions [13]. }\end{array}$ \\
Introduces both physical and statistical factors & $\begin{array}{l}\text { inherently. (Due to the changes in polarity, field } \\
\text { dependent factor ranging from zero to } \\
\text { maximum for each half-cycle). }\end{array}$ & $\begin{array}{l}\text { Both the physical and statistical factors may not be } \\
\text { inherently introduced. }\end{array}$ \\
Magnitude of breakdown field & $\begin{array}{l}\left.\text { Equivalent to peak-to-peak value (2E } \mathrm{E}_{\mathrm{b}}\right) \text { of the } \\
\text { characteristic breakdown stress. }\end{array}$ & Equivalent to the field amplitude $\left(\mathrm{E}_{\mathrm{b}}\right)$. \\
\hline
\end{tabular}




\begin{tabular}{|c|c|c|}
\hline Discharge pulse repetition & $\begin{array}{l}\text { System experiences series of pulses that causes } \\
\text { breakdown when critical value exceeded }\end{array}$ & $\begin{array}{l}\text { No such repetitive pulses exist; Either equilibrium is } \\
\text { eventually established or proceeds to breakdown in a } \\
\text { given time }\end{array}$ \\
\hline Polarisation in uniform dielectric & $\begin{array}{l}\text { Time dependent polarisation generates a } \\
\text { displacement current } 90^{\circ} \text { out of phase with the } \\
\text { field }\end{array}$ & $\begin{array}{l}\text { Experiences a transient behaviour as the polarisation and } \\
\text { current density reduced to their static values }\end{array}$ \\
\hline Risk during service & $\begin{array}{l}\text { Thermal fluctuations and thermal gradient } \\
\text { (intrinsic feature of the system) may occur } \\
\text { during service. }\end{array}$ & $\begin{array}{l}\text { Rapid voltage spikes (lightning strikes on cables) may } \\
\text { occur during service. }\end{array}$ \\
\hline Effect of space charge & $\begin{array}{l}\text { Polarity dependent injection current builds up } \\
\text { the space charge progressively; Local damage } \\
\text { and deformation accumulated will cause fatigue } \\
\text { in the insulation. }\end{array}$ & $\begin{array}{l}\text { Field gradient established as a result of space charge will } \\
\text { age the polymer via electromechanically induced creep } \\
\text { and eventually cause failure. }\end{array}$ \\
\hline Polarity \& type of charge & $\begin{array}{l}\text { Results in injection of homo-charges; In some } \\
\text { cases both homo and hetero charges may be } \\
\text { trapped in same region of the polymer in } \\
\text { unrecombined form. }\end{array}$ & $\begin{array}{l}\text { Injected space charge density slowly drops down and then } \\
\text { reloaded by further injection likely to take place from the } \\
\text { same spot on the electrode. }\end{array}$ \\
\hline Equation for total damage [14] & $\begin{array}{l}\text { Total damage: } \\
S(t)=\left[\frac{L(t)}{L_{b}}\right]^{d_{f}}=\frac{t}{t_{c h}} \text { where } \mathrm{t} \rightarrow \text { ageing time } \\
\mathrm{t}_{\mathrm{ch}} \rightarrow \text { characteristic time for channel formation. } \\
\mathrm{d}_{\mathrm{f}} \rightarrow \text { fractal dimension }\end{array}$ & $\begin{array}{l}\text { Total damage: } \\
S=\left[\frac{L}{L_{b}}\right]^{d_{f}} \\
\mathrm{~L} \rightarrow \text { length of the tree channel termed as } \sigma(\mathrm{L}) \text { denotes } \\
\text { sum of length of all the channels } \\
\mathrm{L}_{\mathrm{b}} \rightarrow \text { average length of a newly created channel. }\end{array}$ \\
\hline
\end{tabular}

In addition to the effects of $\mathrm{AC}$ and DC stresses applied to dielectric systems, it is hypothesized in [15] that the kinetic process of this electrical tree growth as a quantitative description generally involves a combination of electrical and mechanical stresses. This aspect might be based on the fractal nature, structure of electrical tree in an insulating material and the specific physical mechanism. It is evident from the preceding discussions that several additional factors could also influence the nature of treeing initiation and propagation. A few of such major factors include shape \& structure of dielectric material, chemical composition, temperature and humidity.

\subsubsection{Shape \& structure (morphology) of insulating material}

The rapid process of channel formation in a solid insulation does not rely on fatigue mechanism, even though the channel enlargement and progressive extension require discharge or avalanche repetition. Though it does not play the prominent role, the material morphology can be expected to have some effect on tree initiation and growth. Naturally the shape and structure called morphology of the insulating material will affect the formation of tree channel by the extraction and injection current to and from the electrodes through the amount of energy required to produce a channel forming rupture. For the poorer values of the tensile strength of the material, these trees will initiate and grow faster. The primary step in tree initiation is the establishment of a conduit that consists of an extended free volume defects. The presence of such free volume defects in the structure of insulating material prior to the application of electric stress (either AC or DC) can be expected to reduce the tree inception time and the electric field. Further the shape of the electrical tree can be defined through the fractal dimensions either as branch tree or as bush tree. In general, whenever the value of this fractal dimension $\left(\mathrm{d}_{\mathrm{f}}\right)$ is less than 2 , then it should lead to a branched tree; however, when it lies in between 2 to 3 then it must be a type of bush tree. According to [14], branched tree tends to grow at lower voltages and on the other hand bushed tree tends to grow at higher voltages. Another mechanism for discrimination of trees as revealed by [16] indicates five different kinds of tree structures viz. branch, bush, bine-branch, pine-branch and mixed configurations. Such variations may be as a consequence of the impact of uneven congregating state of material, difference in crystalline structure and the existence of residual stress at an instant etc.

\subsubsection{Chemical composition of insulating material}

Notwithstanding the role of yield strength in characterizing the insulating material, the chemical composition of that particular material also has a strong influence in the process of initiating electrical treeing in several mechanisms. Since the effective bond strength of all the polymeric insulating materials are found to be very similar (i.e. in the range of $3.5-4 \mathrm{eV}$ ) as in [17], the contribution towards the damage from the impact of ions and electrons does not significantly affected by the chemical composition of the material. However, the chemical composition of which the insulating material is made of and the type of by-product produced during the discharge may incidentally affect the value of its resistance to chemical erosion.

It is also worth mentioning that, by altering the inception field for discharge in dielectric, the propagation of electrical tree has also been affected majorly by the absorbed gases and the gaseous decomposition products released during the overall process of treeing in a solid insulating material. In this context, in an interface region some form of gases including the concentration of oxygen might be absorbed from the surrounding atmosphere by any of the insulating material in the course of complete treeing process. After making the contact with the metal part, this oxygen which is being considered as an electronegative gas tends to produce some acceptor surface which leads to an inversion region. Therefore, the effective width of the barrier through which an electron injection is taking place reduced drastically and thereby the process of tunneling injection might be facilitated.

During this process, some of the oxygen molecules $\left(\mathrm{O}_{2}\right)$ that are present in the interface region might be raised to an excited and highly reactive state. In this highly reactive state the oxygen may promote some kind of bond scission and thereby facilitate the channel formation during treeing. Since some of the gases that might be absorbed during the treeing process may have higher discharge inception field than other gases at standard temperature and pressure (STP), the effective discharge can be affected by the nature of atmospheric conditions (includes temperature, pressure etc.) that surrounds the insulating material during both the inception and propagation of electrical treeing. In a few other situations, especially in the case of polymers, although some of the acidic gases (oxides of Nitrogen and Sulphur) are produced during the void discharges which subsequently chemically degrade the overall insulation, oxygen is yet the most damaging species present. Therefore, the polymer radicals have been produced by the discharge with oxidation reaction may promote the bond scission and the channel formation. Since these discharges might also produce UV radiations, the insulators that are susceptible to UV degradation might exhibit a large propagation rate for electrical trees.

\subsubsection{Temperature}

In general, the temperature is not often considered as a critical factor that may influence in electrical treeing. But from the very limited range of data available during research studies it appears that at temperatures between room temperature and $100^{\circ} \mathrm{C}$, the 
overall inception time decreases and at the same time the propagation rate also increases. However, the tree inception voltages occur at greater than room temperature even when the materials that are used as insulating material might be degassed Usually such insulating materials have a higher tensile strength in the amorphous regions when the resistance to inception field increases in steps. In this context, higher injection fields are necessary particularly for the injected charges to acquire sufficient kinetic energy for breaking the chemical bonds at these temperatures. Therefore, in general, an increase in temperature may virtually affect both the magnitude of discharge and the extent of damage produced to the dielectric at the channel tip in such a way that the propagation rate may also be increased. Detailed findings reported in [11] indicate that when composite insulating system has been used, the interfacial region between the two different materials in the composite system might be affected directly by the temperature difference. In this case, the electrical trees appear more pointed and narrow at the time of temperature rise, while they tend to be more spread out when the temperature falls.

\subsubsection{Humidity}

Another crucial factor which has an effect on initiation and growth of an electrical tree is the effect of humidity. This aspect is considered to be another important factor that plays a significant role in electrical treeing that directly affects the internal mechanical stress of the insulating material. The effectiveness of the performance of any category of electrical insulation might be greatly degraded by the humidity treatment or water absorption. In this context, [18] uses Discharge avalanche model (DAM) for evaluating the electrical tree propagation rate by the influence of this humidity treatment as well as the water absorption. The Fourier transform infrared spectroscopy (FT-IR) is used in [18] for confirming the water absorption into the dielectric material. In addition, a high resolution X-ray computed tomography (XCT) is also used for determining the structure and the dependence of electrical tree propagation due to the effect of humidity treatment and water absorption. So it can be easily concluded that the humidity treatment on a dielectric material has an effect of enlarging and extending the process of electrical treeing.

\section{A chronological survey on various types of electrical treeing models - an insight}

The process of evolution, propagation and growth in a solid dielectric material can be modeled based on two major categories named as deterministic approach models such as DischargeAvalanche Model (DAM), Field Limiting Space Charge (FLSC) model etc. and stochastic approach models such as NiemeyerPietronero-Wisemann (NPW) model, Dielectric Breakdown Model (DBM), Field Driven Tree Growth (FDTG) model, Diffusion Limited Aggregation (DLA) Model etc. In a few cases, some other approach might also be categorized as hybrid model approach like the one as Self-Consistent Model (SCM). It is evident from the discussion that a few of the interesting models that comes under this hybrid model approach would be most appropriate in the context of complex insulation system.

The models have been depicted in Fig. 3 and summarized in Table 2 as a chronological description for better understanding of various categories of electrical treeing models that may be taken up for studies in the domain of prediction of structure of electrical tree in solid insulating material.

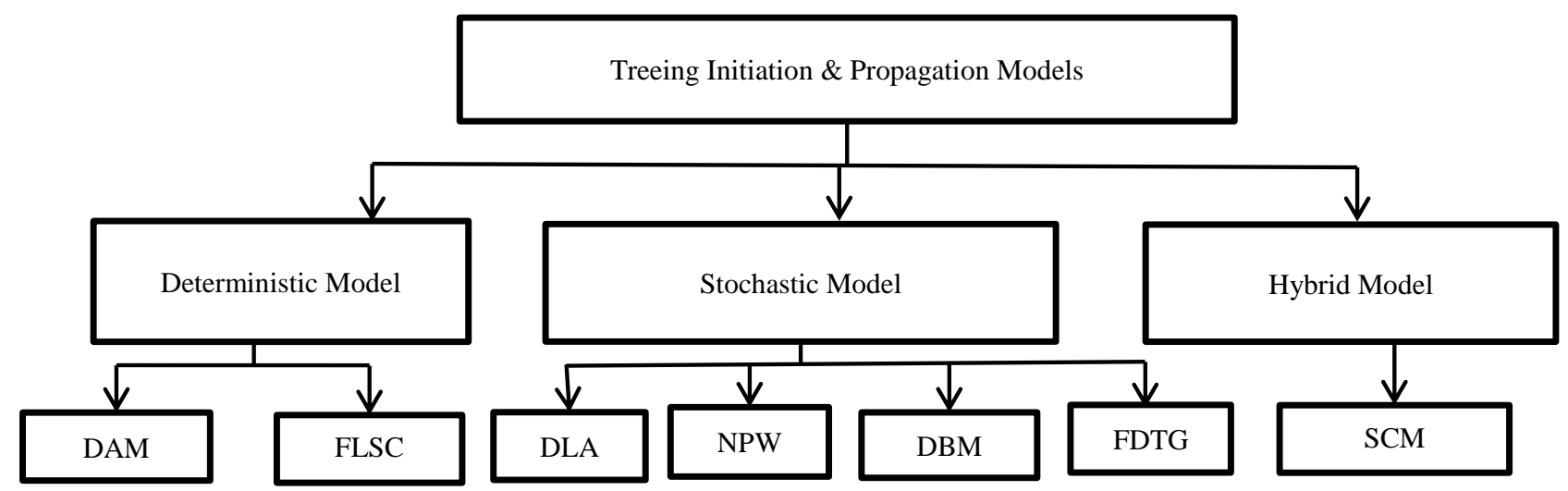

Fig. 3: Chart Depicting Electrical Treeing Initiation \& Propagation Models.

Table 2: Chronological Description on Electrical Treeing Models

\begin{tabular}{|c|c|c|}
\hline Electrical treeing model & Researchers & Unique aspects of the model \\
\hline Discharge Avalanche Model (DAM) & G. Bahder et. al. 1974 & $\begin{array}{l}\text { 1.Space charge in the form of ions is injected into free volume. } \\
\text { 2.Greatest avalanche damage occurs when charge streamers dissipates } \\
\text { into surrounding tree }\end{array}$ \\
\hline $\begin{array}{l}\text { Field Limiting Space Charge (FLSC) } \\
\text { model }\end{array}$ & Zeller and Schneider 1984 & $\begin{array}{l}\text { 1.Electrostatic energy is calculated by using the space charge limited } \\
\text { by field } \\
\text { 2.Change in electrostatic energy is compared with mechanical energy } \\
\text { required }\end{array}$ \\
\hline $\begin{array}{l}\text { Diffusion Limited Aggregation (DLA) } \\
\text { model }\end{array}$ & Witten and Sander 1981 & $\begin{array}{l}\text { 1.Electrical treeing is calculated by recurrent formation of finite } \\
\text { length of channel segments } \\
\text { 2.The dependence of average slope on width of the lattice reaches a } \\
\text { constant value at the shortest correlation radius for a given height of } \\
\text { the tree }\end{array}$ \\
\hline $\begin{array}{l}\text { Niemeyer-Pietronero-Wisemann } \\
\text { (NPW) model }\end{array}$ & Niemeyer et. al. 1984 & $\begin{array}{l}\text { 1.Simplest stochastic model of dielectric breakdown that leads to the } \\
\text { fractal structure of dielectric } \\
\text { 2.Equipotential discharge patterns utilized for determining the local } \\
\text { field related growth probability }\end{array}$ \\
\hline $\begin{array}{l}\text { Dielectric Breakdown Model (DBM or } \\
\eta \text {-model) }\end{array}$ & Wisemann and Zeller 1986 & $\begin{array}{l}\text { 1.Narrow discharge channels are branched into complex stochastic } \\
\text { tree patterns } \\
\text { 2. Only the stochastic process governs the pattern of discharge in the } \\
\text { local field directly }\end{array}$ \\
\hline $\begin{array}{l}\text { Field Driven Tree Growth (FDTG) } \\
\text { model }\end{array}$ & J.V. Champion et. al. 1994 & $\begin{array}{l}\text { 1. Whenever local electric field crosses the value of critical field then } \\
\text { the material damage occurs }\end{array}$ \\
\hline
\end{tabular}




\subsection{Deterministic approach}

The breakdown model which tries to define the balance equations with respect to current or energy density in terms of inter-linked mechanisms are in general represented as deterministic approach In general, the concept of charge injection from electrode, the maximum thermal voltage, the avalanche breakdown strength, the partial discharge and amount of free volume etc. are considered to be the deterministic quantities in the study of electrical treeing. In addition, for providing a detailed insight to the physical processes in electrical treeing, the deterministic approach models have been considered to be meaningful that governs the concept of electrical treeing inception and propagation in a solid dielectric material. A kind of this deterministic approach has been greatly adopted by [19] for modelling the partial discharges (PD) in electrical treeing which is considerably successful in replicating the spatial extent of PD. DAM and FLSC models are being considered to be as deterministic approach models by various authors for modelling the process of electrical treeing.

\subsubsection{Discharge avalanche model (DAM)}

The origin of DAM is first identified and described in Bahder et. al. studies during 1974. Due to the inherent deterministic nature of this representation it has ever since evolved into an interesting physical model which deals with various research aspects for developing the electrical trees from a void or the growth of a new branch from already available electrical tree.

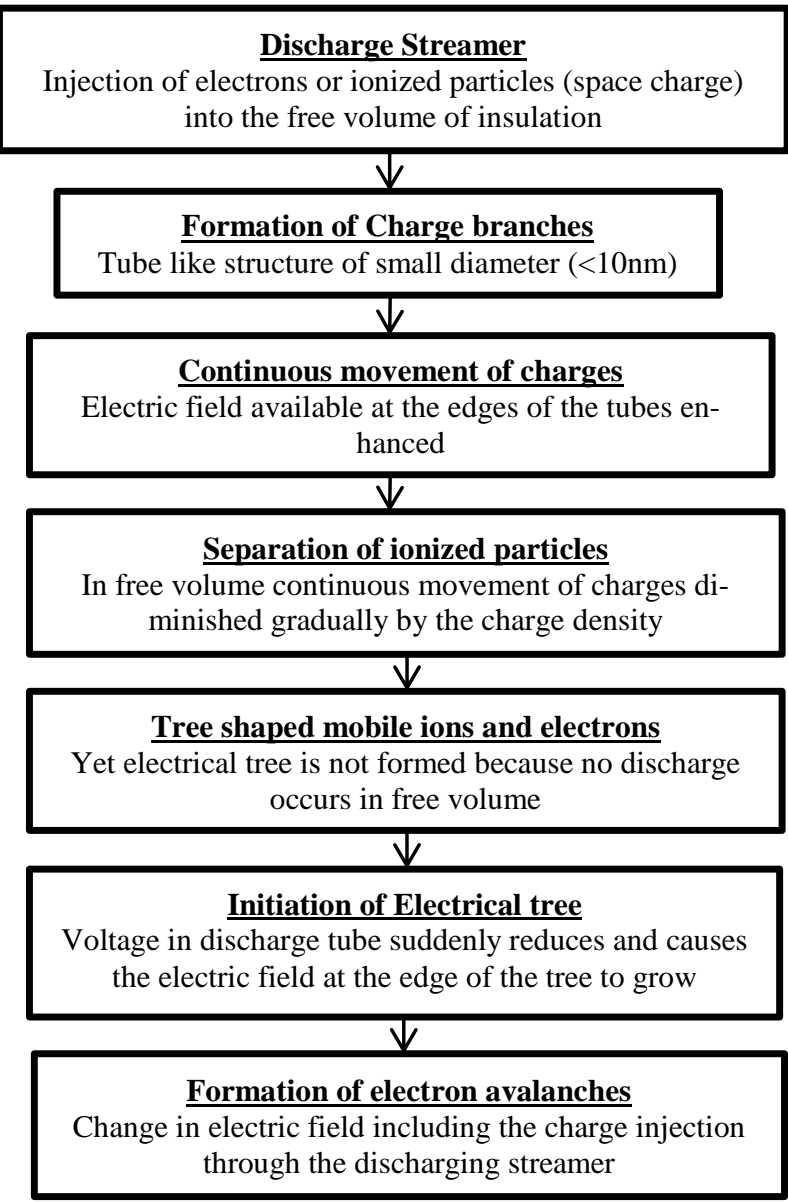

Fig. 4: A Generic Methodology That Describes DAM.
The key factor for controlling tree shape is the availability of injected charges around the tree tip for avalanche participation. It has been identified by [14] that, the progression of electrical tree channel has been driven greatly by an irrevocable damage accumulation in dielectric material. Further, the space charges as electrons or ionized particles in the dielectric are injected in the free volume network through the discharging streamers. During the time of this avalanche discharge in any solid insulating material, there could be a sudden fall in the voltage along with tree channel which in turn causes the sudden change in the electric field which further tends to increase its value. This increase in electric field and the injected charge from discharge streamers results in severe material damage which is caused by the electron avalanches inside the insulations beyond the tree channel. The most noteworthy result of this model as mentioned by [6] is that, in general it could generate branched tree structure in the solid dielectric material. DAM offers considerable capability in providing with details on the transitions observed during real-time studies from branched to bush type trees which usually are a consequence of varying (increasing) applied voltage. A generic methodology that describes the procedure which is utilized in formulating the DAM is summarized in Fig. 4.

\subsubsection{Field limiting space charge (FLSC) model}

If any electrode has the possibility of injecting the charge into a solid insulator, then the space charge cloud may form around that electrode and thereby reduce the available electric field locally. In this context, Zeller and Schneider have proposed the concept of FLSC model in 1984 as espoused in [17] which has been treated as an exact natural progression. Models of this category usually deliberate on the development in terms of a point cathode in an insulator which is capable of injecting the charge, if the applied voltage is such that the field $\mathrm{E}$ is greater than the injected field $\mathrm{E}_{\mathrm{inj}}$. Above the critical field $\mathrm{E}_{\mathrm{mc}}$, the mobility of charge carriers increases sharply from a typical low value and this drastic change of mobility of charge might be considered to be substantially high which in turn might be proposed by a reasonable approximation that, $\mu=0$ when $\mathrm{E}<\mathrm{E}_{\mathrm{mc}}$ and $\mu=\mu_{\infty}$ when $\mathrm{E}>\mathrm{E}_{\mathrm{mc}}$, where $\mu_{\infty}$ denotes high-field limiting value of $\mu$. In the absence of critical field for the mobility of charge, the space charge might inject when $\mathrm{E}>\mathrm{E}_{\text {inj }}$ and diffuses throughout the insulation until the field at the cathode is reduced to $E_{\text {inj }}$ at equilibrium. However, in most of the typical insulation systems, the dynamic situation (i.e. when $\mathrm{E}>\mathrm{E}_{\mathrm{mc}}>\mathrm{E}_{\text {inj }}$ ) has been construed to be very complicated. Initially the injected space charge moves rapidly away from the cathode under the influence of high local field $\left(\mathrm{E}>\mathrm{E}_{\mathrm{mc}}\right)$ while there exists a simultaneous reduction of the local field in the region behind the space charge boundary.

Zeller and Schneider [17] represent the electrical circuitry that simulates treating the space charge cloud as resistors with a parallel shunt and the residual insulation as a series resistance with it. This model circuit representation is depicted in Fig. 5.

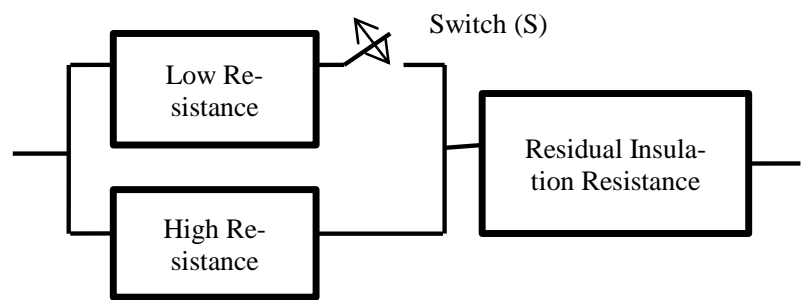

Fig. 5: Electrical Circuitry Denoting the FLSC Model: Switch 'S' Closed at High Field and Open at Low Field. 
In the initial stage, the current might be allowed to flow in the low resistance branch of the circuit which may support only a small quantum of potential difference. As the space charge region tends to extend the field (potential gradient) in this low resistance branch it reaches the value of $E_{\mathrm{mc}}$. Hence, the flow of current automatically switches to the high resistance branch. Obviously the potential drop across the space charge cloud increases whereby the field also rises to a considerable extent and hence the current now switches back to the low resistance branch again. In this manner, the available field within the space charge region could be self limited to $\mathrm{E}=\mathrm{Emc}$. Incidentally, when the boundary field drops below the value of $E_{m c}$ the model shifts to the space charge limited case with the space charge spreading throughout the insulation due to the non-zero low field drift mobility and diffusion.

The basic concept of the FLSC model is considered to be simple and augurs well to compute space charge effect even without having sufficient details of any of the parameters such as the mobility, trap concentration etc. in addition to lack of details on other parameters like $E_{m c}, E_{i n j}$ etc. This aspect can be considered to be in a specific perspective advantageous as the calculation of the space charge distribution in a real time situation might be treated as difficult, yet not impossible. The presence of space charge in the fixed region is predicted correctly by FLSC model whenever the applied voltage to the electrode is maintained constant [20]. However, the model tacitly neglects the small but a finite drift mobility of space charge at low fields.

\subsection{Stochastic approach}

The deterministic approach models for the breakdown of solid dielectrics discussed thus far are characterised by a critical field below which there is no possibility of solid insulation breakdown which might take place in a specific time to breakdown of fields in excess of the critical value. However, in practice, breakdowns are distributed with respect to time at a given field and about a range of fields. So, such models of breakdown which attempt to develop a physical origin for the breakdown of dielectric starting from the traditional NPW model to most other electrical treeing models could in another context also be attempted for better understanding and represented as stochastic approach models. A few major stochastic approach based models are discussed in the subsequent sections.

\subsubsection{Diffusion limited aggregation (DLA) model}

A stochastic model named DLA was introduced by Witten and Sander in 1981. Since then it has been used for extensive studies related to dielectric breakdown more specifically for solid dielectric materials. In order to understand clearly the dielectric breakdown phenomenon in a linear two-dimensional geometry by using this DLA model, a given dielectric is characterized by rectangular $\mathrm{m} x$ $\mathrm{n}$ lattice that might be considered as in [21] whereby the fault that might occur either during the manufacturing process or consequent to dispersion by the nearby metal objects as a conducting particle distends inside the given dielectric material.

The flow chart shown in Fig.6 illustrates the step by step procedure that is involved during the process of simulating electrical treeing using DLA model with the help of Random- Walker principle. Random-walker is in general, a mathematical tool which is treated to be stochastic in nature that describes the succession path with random steps based on a specific physical background. It is hence concluded that the random-walker principle can also be used for the study of electrical treeing. Especially in DLA model, the random walker is initially launched from the opposite electrode and allowed to walk randomly throughout the surface of the electrodes. Once the particular conducting particle from the random walker touches the existing tree structure then it tends to automatically join with that tree structure and lengthens the tree. On the other hand, if by default either it touches the lateral side or the opposite electrode, then that walker might be eliminated completely on its own. This methodology is utilized for describing the initiation and propagation of tree inside a dielectric.

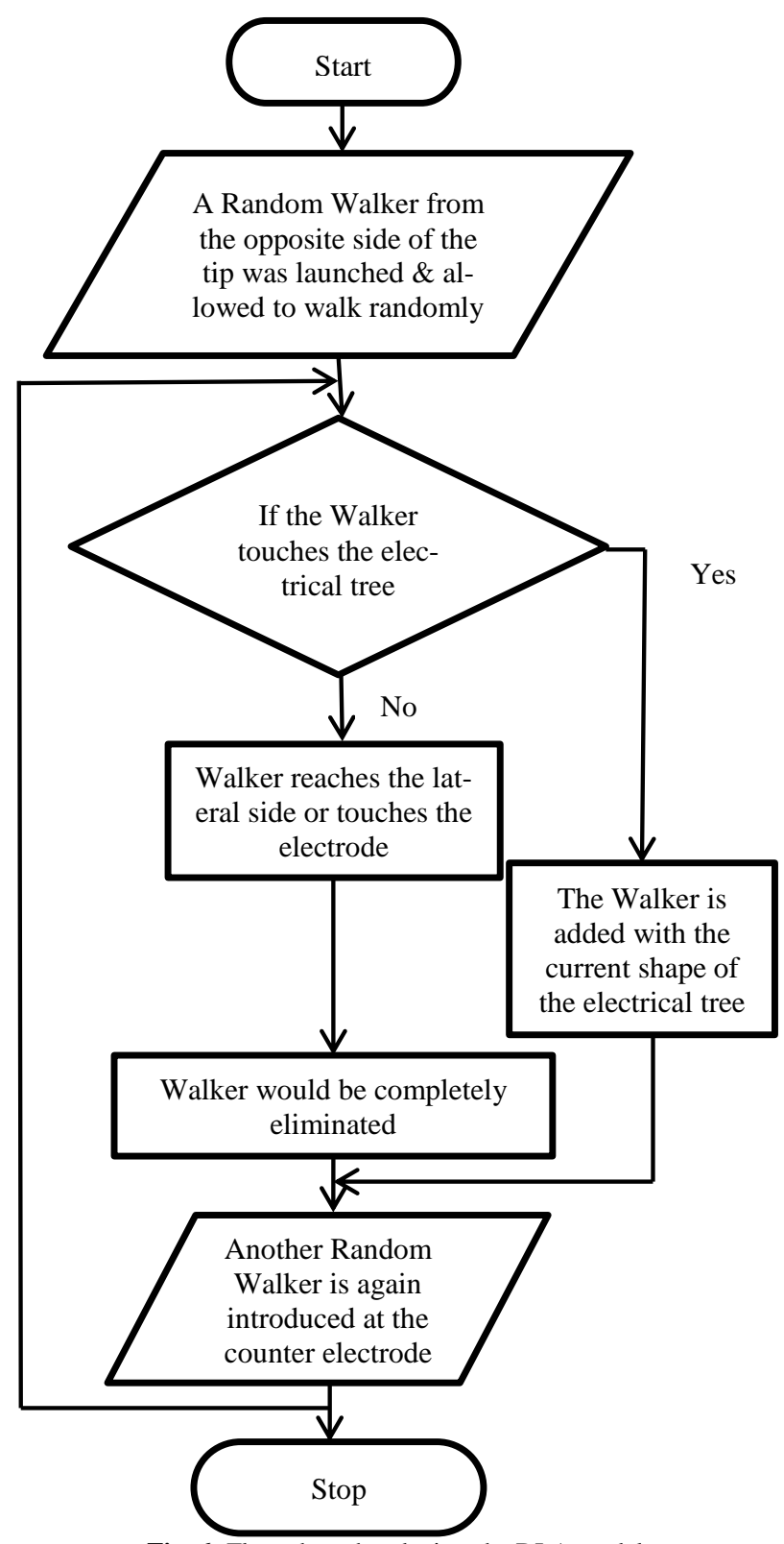

Fig. 6: Flow chart that depicts the DLA model.

\subsubsection{Niemeyer-Pietronero-Wisemann (NPW) model}

Though there have been several models for modelling the electrical treeing in a perfect solid dielectric from as early as 1950s, the NPW model which has been developed in 1984 is considered to be a popular and a most frequently utilized model till date for studies related to electrical treeing. This model has been receiving considerable focus among researchers which may be attributed to simple yet reasonably convincing representation of treeing initiation and modeling due to factors such as field around the dielectric, ageing factor of dielectric etc. including viability to depict fractal structures. In general, in the fractal structure, if a circle of radius $r$ is considered then the relationship between total lengths of all the braches inside a circle with the radius $r$ itself could be a power law with non-integer exponent $\mathrm{D}$.

$\mathrm{N}(\mathrm{r}) \approx \mathrm{r}^{\mathrm{D}}$

The number of branches $n(r)$ at a given distance $r$ from the center is given by, 
$n(r) \approx \frac{d N(r)}{d r} \approx r^{(D-1)}$

Therefore, the information regarding the value of the exponent D could be attained by carefully counting the number of branches available for the given distance $r$. The pattern here grows stepwise. Every point in the lattice shown in Fig. 7 is defined by the Laplace equation including the exact boundary conditions as $\varphi=0$ for each and every point and $\varphi=1$ for any point at the surface of the external circle. The possible bonds are indicated by the dotted lines, which denote that the probability is associated as a function of local field. One of the all available bonds which have the highest value of local field is added with the lattice simultaneously at the end of each step. For instance, the lattice point exist within the circle at the extreme right side of Fig. 7 could have a large growth probability while on the other side it could be much smaller (This kind of effects in the lattice is known as the 'tip-effect' or 'Faraday screening' [22]). Further it is essential to note that no crossing between the bonds is possible; hence the pattern is always connected. Therefore, the essence of this NPW model is that the growth rate of electrical tree is directly related with the development of local fields which are being determined by their equipotential discharge patterns.

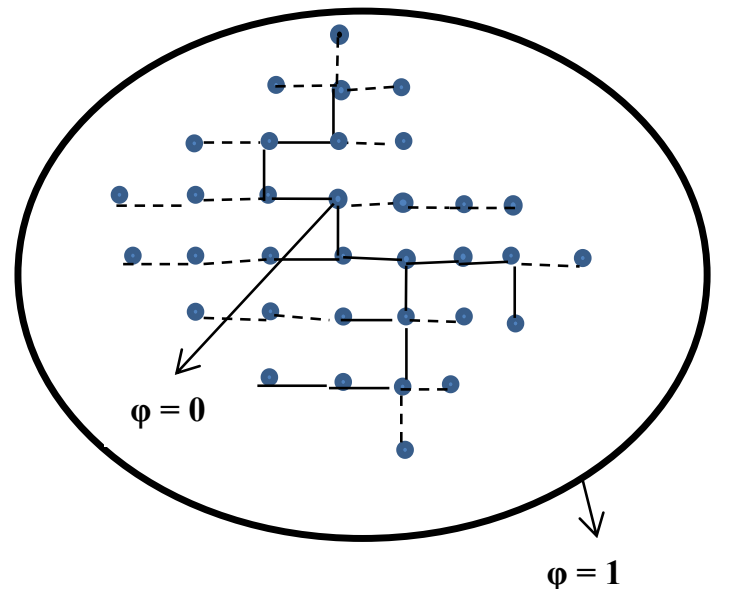

Fig. 7: The Growth Pattern Defined by NPW Model: $\Phi=$ Present Value of Electric Field.

The original NPW model allows the simulation of electrical treeing patterns using several methodologies that includes finite element method, cellular automata etc. Several studies have been undertaken by researchers to match the figures obtained from electrical tree with those of the Lichtenberg figures, in addition to matching these with the fractal dimensions of electrical treeing that could have been produced experimentally in the laboratories as in [23].

\subsubsection{Dielectric breakdown model (DBM)}

The mathematical model suggested by Niemeyer et. al. in 1984 and generalized later by Wisemann and Zeller in 1986 describes the pattern and shape of the dielectric breakdown in solids in the form of treeing structures and is subsequently named as the Dielectric Breakdown Model (DBM). It might, in another context, also be treated as a derived model from the NPW model and at the same time recombines the DLA model with the electric field. This DBM model approach for electrical treeing suggests that the progress of the electrical tree channel is majorly overseen by the surrounding electric field as in [24]. It might be considered that the probability of tree growth is proportional to the value of power available at the local field. This local electric field required for the growth of electrical tree and the potential drop along the discharge structured (DS) channel as mentioned in [25] allows the simulation of electrical tree growth for a variety of DS forms (i.e. linear, bush \& dendrite like structures). Further for better understanding of DBM model for electrical tree growth, the pattern shown in Fig. 8 is considered wherein a few segments are depicted with thick (continuous) lines and a few other segments are indicated with dashed lines which represent the possible candidates for the growth process.

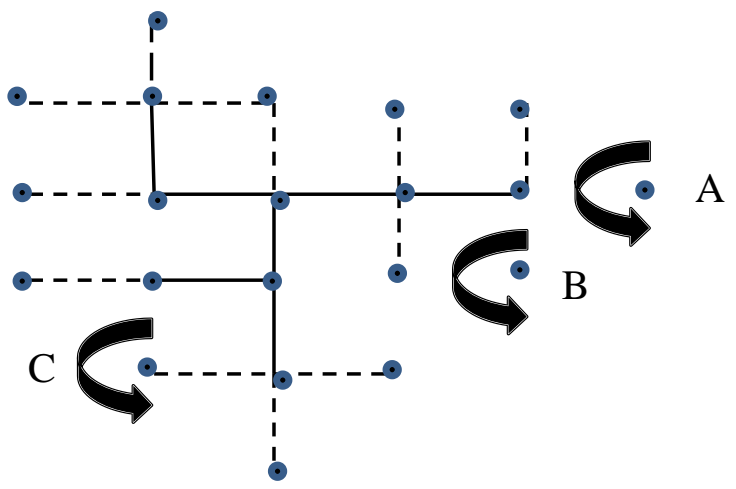

Fig. 8: Pattern Showing the Segments Related with DBM.

By obtaining the solution to Laplace equation with appropriate boundary conditions for Fig. 8, it is possible to obtain the local electric field $\left(E_{j}\right)$ values for all the dashed segments. For the process of assessing the avalanche generation, the two important time frames required for the calculations are: 1 . time required to generate the initiator electrons $\left(\tau_{0}\right)$ and 2. time taken for avalanche propagation $\left(\tau_{\mathrm{av}}\right)$. The value of $\tau_{0}$ is not influenced by the local electric field $\left(\mathrm{E}_{\mathrm{j}}\right)$; contrarily $\tau_{\mathrm{av}}$ is connected with active phenomenon due to the local electric field $\left(E_{j}\right)$ and definitely influenced by E [26]. Therefore, the time required to advance a step distance (d) is generally given by,

$\tau_{a v}(E) \cong \frac{d}{V_{a v}(E)} \cong E^{-1}$

And the time taken to add a new bond

$\tau(E)=\tau_{0+} \tau_{a v}(E)$

In Fig. 8, the points A \& B are considered to be the growing bonds (segments). Since bond A is located at the tip, it is imperative that it has a comparatively huge local field than bond B (i.e. E(A) > $\mathrm{E}(\mathrm{B}))$. If it is being considered that the two avalanches may initiate without any time delay at both the bonds A \& B together, then the avalanche at bond A might reach the preceding pattern quickly as compared to bond $\mathrm{B}$. Therefore, in this condition, bond $\mathrm{A}$ is added next successfully with the discharge pattern as a continuous segment. Meanwhile, the avalanche at bond B has already half developed (as another segment) when the one at bond A completely completes the pattern. It is obvious from the above discussions that in this DBM model, at all times, can choose the nearest bond which is having the largest value of local electric field.

\subsubsection{Field driven tree growth (FDTG) model}

FDTG model suggested and developed by J.V. Champion et. al. in 1994 assumes that the material damage could definitely occur whenever in a dielectric, local field exceeds the material dependent critical field as described in [27]. In general, during the PD activity inside the dielectric material, the tree structure may seem to be conducting and at the same time, may alter the conditions of existing local field by reducing the gap distance between the needle-plane separations effectively. This in addition, is also enlarging the superficial needle tip radius. In this model the tree growth could be equalized to a conducting hyperboloid considered with the radius equal to the length of the tree size and it is denoted by its equipotential lines. In this context, the growth process of electrical trees is modeled by making the assumption that it might be completely based on the value of available local electric field $\left(\mathrm{E}_{\mathrm{L}}\right)$. In this connection, it is desirable to incorporate the time period as explained in [28] whereby it is assumed that considerable change in the damage volume $(\Delta \mathrm{V})$ during each cycle has been improved to the value which is proportional to the value of $\left(E_{L}-E_{c}\right)$, when $E_{L}$ is greater than $E_{c}$, zero otherwise. Therefore, 


$$
\Delta \mathrm{V}=\mathrm{A}\left(\mathrm{E}_{\mathrm{L}}-\mathrm{E}_{\mathrm{c}}\right)
$$

where $\mathrm{A}$ is a constant that depends on the material.

It may be concluded that this FDTG model could be designated by a few major constraints which has an impact on the growth process of electrical tree such as the material dependent electric field $\left(\mathrm{E}_{\mathrm{c}}\right)$, the local electric field $\left(E_{L}\right)$, the fractal dimension $\left(d_{f}\right)$ and finally the applied voltage (V).

\subsection{Hybrid model approach}

Some of the models which are available in the field of research for the study of electrical tree propagation may be of deterministic nature in a few facets and of stochastic nature in a few other aspects whereby necessitating the evolution of a new approach for modelling referred as hybrid model. The self-consistent model (SCM) is one such approach which may be considered both as deterministic as well as stochastic for analysing the properties of electrical trees in solid insulating materials. In addition to SCM, the electrical equivalent model proposed by [29] may also be considered to be a part of the category of hybrid model approaches.

\subsubsection{Self-consistent model (SCM)}

Though DBM and DAM models describe considerably convincingly the fractal features of electrical tree growth they suffer from limitations such as correlation of Partial Discharge (PD), and the role of distribution of electric field that could have been formed as a consequence of space charge etc. In general, [30] portrays the electrical treeing propagation in the solid insulating material as a self-organized criticality (SOC) phenomenon [31] which has been proposed by Bak et. al. Incidentally, the electron avalanches, electromechanical fracturing, photo degradation etc. are considered to be different kinds of mechanisms that are potential likelihoods for the solid dielectric destruction due to PDs. These mechanisms could respond simultaneously for the process of electrical treeing and at the same time they tend to stimulate each other at that instant Therefore, the SCM which has been postulated by [25] associates concurrently both the tree growth phenomenon due to the existence of local electric field as well as the PD events ensuing in the channels of electrical tree inside the dielectric. Quite similar to DBM and DAM models, in the SCM also, a rectangular lattice is used whereby it is possible to simulate the tree channels by using one-dimensional sequences of the available lattice points. The possible directions of channel formation as electrical tree are controlled or decided by the rectangular mesh and on the other hand it is assumed that the diameter of the channel must be equal to the surface of the available lattice grid. In order to circumvent these limitations, it is necessary to have a perfect non-lattice model for analysing the electrical tree growth. Thus, the self-consistent model may be treated as one such representation.

During the process of analysing the electrical tree growth using SCM, charge simulation method (CSM) based on Coulomb's law and the field superposition principle has been taken up in [23] for the computation of local electric field inside dielectric material. It is essential to note that, the tree growth process is significantly governed by the creation of local electric field around the electrodes including the damage accumulation that is possible in and around the existing tree channel. Utilizing this model, the distribution of electric field in the dielectric material can be identified with the aid of the quantity of charge deposition around the already existing electrical tree and also by the type of electrode configuration that is used in the dielectric. In this context, as hypothesized in [23], the phenomenon of PD plays a vital role in modelling the electrical tree growth. Therefore, within the dielectric material the PD activity and electrical treeing occur simultaneously. Thus this self-consistent mechanism results in the widespread degradation of the insulating material. The process of PD in the dielectric starts whenever the electric field along the tree channels goes beyond the predefined threshold inception range and stops whenever this electric field again drops down below the specified threshold limit. Hence a few of the salient highlights of the SCM is summarized lucidly for a needle-plane electrode configuration. A brief account on SCM representation for treeing propagation includes a few significant aspects such as:

- Major criteria namely damage build-up and electric field (which are treated as origin of channel growth) can be deciphered by investigating the physics of damage mechanism or on the basis of experimental data.

- When the available damage energy is not as similar to that of the critical value or if the local electric field is not as much as that of the critical field then the possibility of tree growth is less and even zero.

- Only when the local damage energy touches the critical value and at the same time when the local field surpasses the critical field, the new channel might be formed immediately near the prevailing tree structure.

- During this channel formation, transfer of charge takes place due to the occurrence PD inside the dielectric along with the existing walls of the tree channels.

- There exists the electron avalanche formation, wherein the liberation of electrons owing to ionization reaches beyond the level of loss of electrons owing to the recombination and attachment process.

- A considerable movement of charge inside the tree channel can produce the electric field distortion which further creates the pre-requisite for discharge elimination.

- After the discharge elimination, a firm residual field is discerned along with the existing tree channels.

- Based on the preceding discussion, the PD ignition and elimination can be better described with the aid of the threshold dependence on local field.

\subsubsection{Electrical equivalent model}

At the outset, [29] attempted to obtain an electrical equivalent model for electrical treeing discharge. According to this model, the time derivative of the applied voltage ( $\mathrm{dv} / \mathrm{dt}$ ) influences strongly the PD activity that is occurring in the process of electrical treeing and at the same time the magnitude of it is also calculated with the help of the value of applied voltage. Therefore, an equivalent circuit of this electrical tree can be obtained by measuring and analysing the PD patterns due to electrical treeing process in case of solid insulating material.

The circuit shown in Fig. 9 (a) \& (b) indicates the equivalent circuit for the electrical tree and that could be characterised by a spark gap $\mathrm{S}_{\mathrm{gp}}$, capacitances $\mathrm{C}_{1}, \mathrm{C}_{2}$ and a small resistance $\mathrm{R}_{1}$. In the circuit, the capacitance $\mathrm{C}_{1}$ denotes the healthy part of the insulation which is connected in series with capacitance $\mathrm{C}_{2}$ which in turn is connected in parallel to the spark gap that represents the effective length of the tree channel. In this circuit the small resistance $R_{1}$ is configured / arranged in series with the complete arrangement to facilitate performing the role of time derivative of the applied voltage during the occurrence of PD. The effective potential across this series resistance $R_{1}$ is always proportionate to the value of time derivative of the applied voltage and it can be treated as actuating voltage for the PD occurrence in the spark gap.

(A)

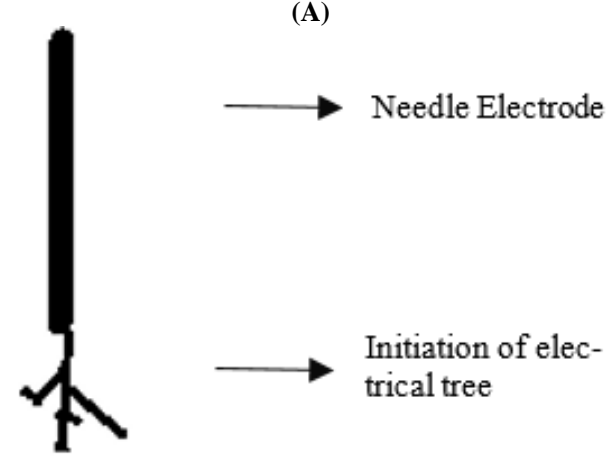


(B)

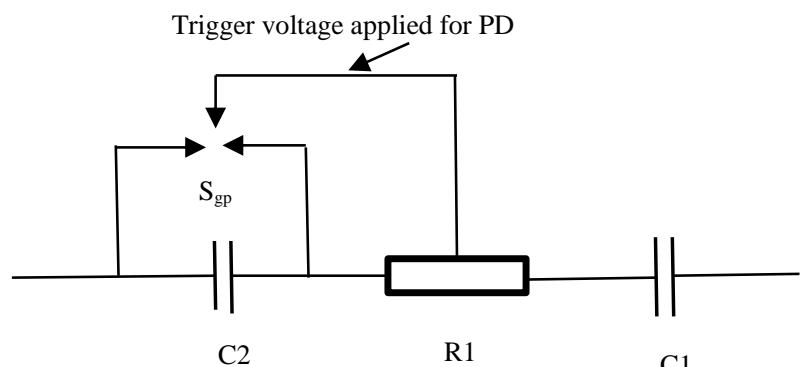

$\mathrm{C} 2$

R1

Fig. 9: (A). Formation of Electrical Tree at A Needle Tip. (B) Single Channel Electrical Equivalent Circuit of Electrical Tree: $\mathrm{C} 1=$ Healthy Part of Insulation, $\mathrm{C} 2=$ Tree Channel, R1 = Small Resistance for Time Derivative of Applied Voltage, $S_{\mathrm{gp}}=$ Spark Gap.

However, due to the presence of very little free charges inside the dielectric, it is impossible to ignore the effect of space charge completely and hence the space charge effect is also considered in obtaining the equivalent circuit of electrical treeing. In this context, the solution of Laplace's equation can be obtained in order to ascertain the nature of potential distribution in the total treeing process. Sometimes the Poisson's equation may also be solved with respect to this model for simulating the propagation of electrical tree along with the effect of space charge present in the dielectric. In this model the effective electric field E could be approximated by,

$$
E=\varepsilon \frac{V}{a}
$$

Where $\mathrm{V}$ represents the voltage difference between two cells, $\varepsilon$ denotes dielectric constant and a indicates distance between the center of cells

\section{A perspective on statistical modelling meth- ods for treeing based degradation studies}

The statistical modelling method is considered to be one of the most suitable modelling techniques available for modelling the electrical trees since by using each of the test samples it would enable obtain different results for different test conditions. The three major distribution functions that are concerned to be significant statistical modelling methods applicable for the treeing based degradation studies are Weibull distribution, Log-normal distribution and Johnson SB distribution.

Among the three distributions, Weibull and Log-normal distributions are found to be unique and at the same time frequently used distribution functions which deal with the probability of failure in case of solid insulations. In recent times, Johnson SB distribution has also been used widely for the analysis of failure rate statistics in solid dielectrics. In this connection, a brief discussion with a comparison on the three distributions have been summarized in [28] and Table 3 in order to compare the salient features distinguishing the statistical distribution techniques for prediction of failure due to varying characteristics of electrical treeing in solid insulation systems. This comparison includes two important generic functional equations such as the Probability density function (pdf) and the Cumulative distribution function (cdf).

Table 3: Comparison Between Different Statistical Distribution Functions

\begin{tabular}{|c|c|c|c|}
\hline Description & Weibull distribution & Log-normal distribution & Johnson SB distribution \\
\hline Characteristics modeled & $\begin{array}{l}\text { Tree breakdown time, breakdown } \\
\text { voltage, tree length in solid insulation }\end{array}$ & $\begin{array}{l}\text { Failure of components' life due to } \\
\text { fatigue stress, tree length distribution }\end{array}$ & Tree inception voltage \\
\hline Important parameters & $\begin{array}{l}2 \text { Parameters: scale }(\alpha) \text { and shape }(\beta) \\
\text { parameters, } \\
3 \text { Parameters: } \alpha, \beta \text { and location } \\
\text { parameter }(\mathrm{x} 0)\end{array}$ & $\begin{array}{l}\Phi \rightarrow \text { Laplace integral } \\
\mu \rightarrow \text { logarithmic mean (scale parameter) } \\
\sigma \rightarrow \text { logarithmic standard deviation }\end{array}$ & $\begin{array}{l}\delta, \gamma \rightarrow \text { shape parameters, } \xi \rightarrow \\
\text { location parameter, } \lambda \rightarrow \text { scale } \\
\text { parameter, }\end{array}$ \\
\hline \multirow[t]{2}{*}{$\begin{array}{l}\text { Generic } \\
\text { function }\end{array}$} & $f(x)=\frac{\beta}{\alpha}\left(\frac{x}{\alpha}\right)^{\beta-1} \exp \left[-\left(\frac{x}{\alpha}\right)^{\beta}\right]$ & $\mathrm{f}(\mathrm{x})=\frac{1}{x \sigma \sqrt{2 \pi}} \exp \left(-\frac{1}{2}\left(\frac{\ln x-\mu}{\sigma}\right)^{2}\right)$ & $\begin{array}{l}f(x)=\frac{\delta}{\lambda \sqrt{2 \pi}} \exp \left[-\frac{1}{2}(\gamma+\right. \\
\left.\left.\delta \ln \frac{z}{1-z}\right)^{2}\right]\end{array}$ \\
\hline & $\mathrm{F}(\mathrm{x})=1-\exp \left[-\left(\frac{x-x 0}{\alpha}\right)^{\beta}\right]$ & $F(x)=\Phi\left(\frac{\ln x-\mu}{\sigma}\right)$ & $F(z)=\emptyset\left(\gamma+\delta \ln \left(\frac{z}{1-z}\right)\right)$ \\
\hline $\begin{array}{l}\text { Estimation methods for the } \\
\text { parameters }\end{array}$ & $\begin{array}{l}\text { Least square method, maximum } \\
\text { likelihood estimation, plotting by } \\
\text { analytical procedures }\end{array}$ & Laplace integral & Maximum likelihood estimation \\
\hline Applications & LDPE, XLPE & Water treeing -Cables & Silicone rubber and epoxy resin \\
\hline $\begin{array}{l}\text { Goodness-of-fit test (fitting } \\
\text { error) }\end{array}$ & $\begin{array}{l}\text { Failure of insulation as a function of } \\
\text { time but not necessarily of voltage } \\
\text { stress }\end{array}$ & $\begin{array}{l}\text { The arithmetic convenience of having } \\
\text { log-lifetimes normally distributed }\end{array}$ & $\begin{array}{l}\text { Anderson-Darling (AD) } \\
\text { goodness-of-fit test for tree } \\
\text { inception voltage }\end{array}$ \\
\hline
\end{tabular}

In addition to the aforesaid three statistical distribution functions for modeling of electrical treeing another noteworthy distribution function named 'Gamma distribution' is also considered which plays an interesting role in research studies related to the statistical modelling of electrical treeing. In [32], Gamma distribution function has been used as a statistical modelling technique for analysing the electrical tree growth in flexible epoxy resin. The applied voltage, average power per discharge, energy dissipated per cycle and tree growth time is identified as some of the important characteristics that are modeled with the help of the Gamma distribution in [32]. The probability density function (pdf) of the distribution function is given by equation (7):

$$
f(x \mid a, b)=\frac{1}{b^{a} \Gamma(a)} x^{a-1} e^{\left(\frac{x}{b}\right)}
$$

It has both the scale (b) and shape (a) parameters. Other important parameters also considered for this statistical distribution function (gamma) include the Mean $(\mu)$, Standard deviation $(\sigma)$, skewness and kurtosis excess (k).

\section{Overview \& analysis of numerical methods - A comparison}

There are various numerical methods available in research studies related to modelling and analysis of electrical treeing mechanism in solid insulating materials. Each of these numerical methods has some distinct advantages as well as disadvantages depending on the actual aspect of modeling to be comprehended and thus these methods are to some extent complementary. Some of the important numerical methods that have been taken up by research studies like [8], [23], [30] etc. thus far include Finite Difference Method (FDM), Finite Element Method (FEM), Boundary Element Method (BEM) and Charge Simulation Method (CSM) etc. In a few other significant research studies such as [33]-[34], Genetic Algorithm (GA) has also been implemented as a hybrid structure for obtaining estimates of electric field and voltages during treeing propagation studies along with FEM for accurate modelling of electrical trees in solid dielectrics. Aspects related to such numerical methods and its implementations in treeing propagation studies is deliberated for 
providing a better understanding of its effectiveness during modeling studies and analysis.

\subsection{Finite difference method (FDM)}

Finite difference method (FDM) is considered to be a powerful numerical method that is useful in analysing the growth process of electrical tree in perfect solid dielectrics. It uses the partial differential equations for its computations. Since any irregular surfaces may lead to inadequate difference equations whereby leading to prohibitively complex numerical computations, FDM augurs well as it conveniently divides the available irregular shape to the regular shapes of polygons. The points of intersection between the vertical and horizontal lines are called 'nodes' wherein the potentials are known either by boundary conditions or by other computational methods. As the potential within the field region is continuous it is obvious that the potential at any point in the field region by utilizing the Taylor's series expansion. By considering the point $\mathrm{P}$ with $(\mathrm{x}, \mathrm{y})$ co-ordinates, the potential at any point $(\mathrm{x}, \mathrm{y})$ is given by,

$$
\begin{aligned}
& \varphi(x, y)=\varphi(P)+\frac{1}{1 !}\left[\left(x-x_{p}\right) \varphi_{x}(P)+\left(y-y_{p}\right) \varphi_{y}(P)\right]+ \\
& \frac{1}{2 !}\left[\left(x-x_{p}\right)^{2} \varphi_{x x}(P)+2\left(x-x_{p}\right)\left(y-y_{p}\right) \varphi_{x y}(P)+(y-\right. \\
& \left.\left.y_{p}\right)^{2} \varphi_{y y}(P)\right]+
\end{aligned}
$$

The FDM is used to obtain the estimate of the space charge limited current due to air corona discharges in [35]. In general, while using finite difference method for carrying out specific analysis in the study of electrical treeing the most commonly defining aspects include:

- A partial differential equation such as Laplace's equation, Poisson's equation etc.

- A well-defined solution region

- Boundary condition and initial conditions

During the implementation of FDM, the overall domain considered for obtaining the comprehensive solution can be divided into a number of distinct points of finite size which in turn replicates the existing PDE with a group of ordinary difference equations. It is evident from the formulated proposition that it would be complex to obtain the exact solution utilizing the proposed formulation of FDM though it could still be possible to obtain some approximate solution for the given problem. It is also obvious from the discussion that though the solution could result into approximations, if judicious choice of number of divisions of distinct points is made appropriately to resolve into unique sets, it is possible to reduce the error in the solution to a satisfactory level.

\subsection{Finite element method (FEM)}

Finite element method (FEM) has been extensively used by several researchers for analyzing the concept of electrical tree in solid dielectrics which can be invariably categorized into five different procedures which has also been deliberated in [36]. These categories include:

- Determining the perfect geometry of the model

- Enmeshing the total geometry

- Assigning appropriate boundary conditions

- $\quad$ Solving the PDE and

- Carrying out post-processing and result analysis

At each step of the above mentioned procedures, a few specific techniques have been used to achieve the requisite accuracy during the computation of electric field. It is evident from [23] that several researchers have taken up utilizing NPW model for modelling electrical treeing wherein FEM has been implemented for estimating the specific parameters that govern treeing growth. A few studies carried out by researchers like [8] based on MATLAB indicate implementation of Partial Differential Equation (PDE) Toolbox along with the aid of Graphical User Interface (GUI) to enable obtain a fairly accurate solution for either Laplace's or Poisson's equations. PDE that utilizes FEM is considered as a powerful tool and finds wide applications in a gamut of other allied fields such as acoustics, heat diffusion, various scattering problems etc. With almost all of the applications involving solutions based on numerical methods, the FEM strive for the accurate solutions to the complex spatial-temporal and complexities in solving differential equations based on specific realistic interpretations meaningfully evaluated, quantified with a few possible errors yet in a holistically acceptable manner. In order to compute the value of the space charge modified field, [12] utilizes the FEM with proper boundary conditions and after every tree segment is added with the present tree. Consequently, the field is recalculated for the new boundary conditions. Further, [37] uses FEM for estimating the potential, electric field and space charge density distribution under steady state in a solid electrical insulation. In addition, [38] also implements the concept of FEM for the field profile calculations with respect to the space charge density in a polyethylene embedded with a needle tip electrode.

\subsection{Charge simulation method (CSM)}

Charge Simulation Method (CSM) is relatively simple and applicable to any kind of systems that must include one or more homogeneous media. In this context it is worth mentioning that in [30], an accurate computation of electric field is considered to be a pre-requisite for the determination of mode and calculating the growth of electrical tree. Hence, the CSM is used in [30] for computation related to electric field distribution. In a few other distinct and specific requirements, wherein self-consistent models are implemented, the CSM is most appropriately used and in most cases are based on applying Coulomb's law and the field superposition principle for the estimation of electric field.

\subsubsection{CSM based on Coulomb's law and the field superposition principle}

It is worth mentioning that while carrying out analysis of electric field using the method of images, the distribution of electric field is significantly affected due to the presence of a plane electrode which is considered to be at zero potential (assigning the corresponding images of the charges with those of the opposite polarity to the back of the plane). Since in the method suggested by [23], the needle electrode described by a paraboloid of revolution implements the initial field distribution even in the absence of electrical tree, the field might be construed logically to be an arrangement of a large number of point charges around the paraboloid so as to obtain the sequential alteration $\varphi(t)$ on electrical treeing. By carrying out simulation studies utilizing an appropriate modeling software as indicated by [30], it is made evident that the normal point charges situated at an equal distance $\mathrm{d}$ from each other and thus the shape of the electrical tree could be exemplified by a completely connected assembly of adjoining spheres with the value of its radius $\mathrm{r}=\mathrm{d} / 2$ which determines the minimal space scale as shown in Fig. 10 . 


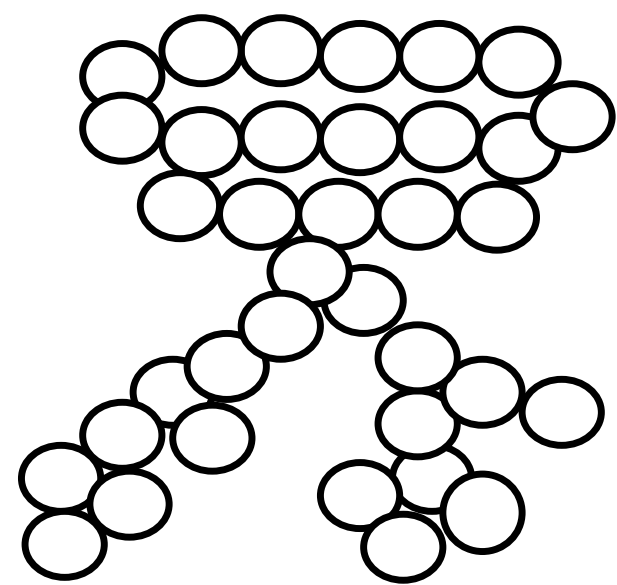

Fig. 10: One-Dimensional Point Charges Located at an Equal Distance Forming A Tree Structure.

It is observed that the potential $\varphi_{i}^{n}$ of $i$-th sphere in the total structure is attained by summing all the individual potentials produced by its own charge $q_{i}^{n}$ and the potentials at all the remaining charges is represented by the equation (9),

$\varphi_{i}^{n}=\frac{q_{i}^{n}}{4 \pi \varepsilon \varepsilon_{0} r}+\sum_{j \neq i} \frac{q_{j}^{n}}{4 \pi \varepsilon \varepsilon_{0}\left|\vec{r}_{i}-\vec{r}_{j}\right|}$

Where vector $\mathrm{r}_{\mathrm{j}}$ represents the actual location of real or image charge $\left(\mathrm{q}_{\mathrm{j}}\right), \varepsilon$ stands for the relative permittivity, $\varepsilon_{0}$ indicates the absolute permittivity and the summation $(\Sigma)$ denotes the computation carried out for all the charges (excluding the real $i$-th charge) available in the tree structure as well as the needle and the appropriate image charges that are caused due to the mirroring action of all the real charges that are available in the plane electrode.

\subsection{Boundary element method (BEM)}

In Boundary element method (BEM), the basic concepts and equations of the electromagnetic field theory has been extensively used for obtaining the appropriate boundary conditions. These boundary conditions are applied at the insulating particle boundaries which can offer possibilities of obtaining interesting results during simulation of electrical tree propagation. In BEM, the unknown function is initially solved based on the boundary of the domain. Subsequently, the unknown function and its partial derivatives are computed based on the integration of number of boundary elements. It is hence evident that it is possible to reduce the number of elements and the number of unknowns in the resulting linear equations as compared with FDM and FEM.

In general, researchers like [38] used the BEM concept for the calculation of electric field profile for the needle tip which has been embedded in polyethylene which in addition considers the presence of space charge. It has been observed that according to BEM, the minimum value of space charge density $\left(2.27 \times 10^{-3} \mathrm{C} / \mathrm{cm}^{3}\right)$ is sufficient to reduce the electric field at the needle tip to zero. In addition, it is interesting to note that the major limitation of this method is that it may take substantial time for estimation because of the presence of all the boundary elements (needle electrode, plane electrode, conducting particle, interfaces between the dielectric and the surrounding air) that could be considered for computation of total electrical field. However, according to [39], reduced computational cost and memory requirements are observed during the implementation of BEM which utilizes Fast multi-pole (FM) (a model containing floating conductors and multiple dielectrics) to solve potential problems in electrical treeing.

In order to provide a clear understanding of the outcomes during the implementation of various numerical methods, a recap of the unique contributions by researchers is summarized in Table 4 .

Table 4: Literature on Various Numerical Models

\begin{tabular}{|c|c|c|c|}
\hline Numerical Method used & Researcher & Model / Material used & Contributions / Findings \\
\hline \multirow[t]{2}{*}{$\begin{array}{l}\text { Charge Simulation Method } \\
\text { (CSM) }\end{array}$} & M D Noskov et. al. [25] & SCM in epoxy resin & $\begin{array}{l}\text { 1. Key constraints that determine the treeing } \\
\text { behaviour } \\
\text { - Threshold specific energy } \mathrm{W}_{\mathrm{c}} \text {, } \\
\text { - } \quad \text { critical field } \mathrm{E}_{\mathrm{c}} \text {, } \\
\text { - } \quad \text { ignition field } \mathrm{E}_{\mathrm{ign}} \text {, } \\
\text { - } \quad \text { residual field } \mathrm{E}_{\mathrm{res}} \text {, } \\
\text { - } \quad \text { applied voltage and } \\
\text { - } \quad \text { electrode gap geometry } \\
\text { 2. Though this research deals with epoxy resin, the } \\
\text { conclusions and results are invariably applicable to } \\
\text { other dielectrics too }\end{array}$ \\
\hline & A. El-Zein et. al. [34] & Numerical Model & $\begin{array}{l}\text { 1. Critical number of cracks }\left(\mathrm{n}_{\mathrm{c}}\right) \text { inside the } \\
\text { dielectric is guessable since it is always equal to the } \\
\text { fractal dimension }\end{array}$ \\
\hline $\begin{array}{l}\text { Finite Element Method } \\
(\mathrm{FEM})\end{array}$ & $\begin{array}{l}\text { Simon M. Rowland et. al. } \\
{[36]}\end{array}$ & $\begin{array}{l}\text { 3-D image based model in } \\
\text { polymers }\end{array}$ & $\begin{array}{l}\text { 1. 3-D structures by XCT and SBFSEM techniques } \\
\text { provides tremendous models with more features } \\
\text { above a micro meter } \\
\text { 2. Dielectric properties of polymer at the tip of the } \\
\text { tree are necessary for a realistic model }\end{array}$ \\
\hline
\end{tabular}

In this context, in addition to the detailed discussions carried out thus far related to numerical methods used by several researchers, Fig. 11 provides a succinct depiction of the various techniques used as the prediction tools based on different numerical methods considered for prediction of initiation, growth and shape of the electrical trees in any solid insulating material. 


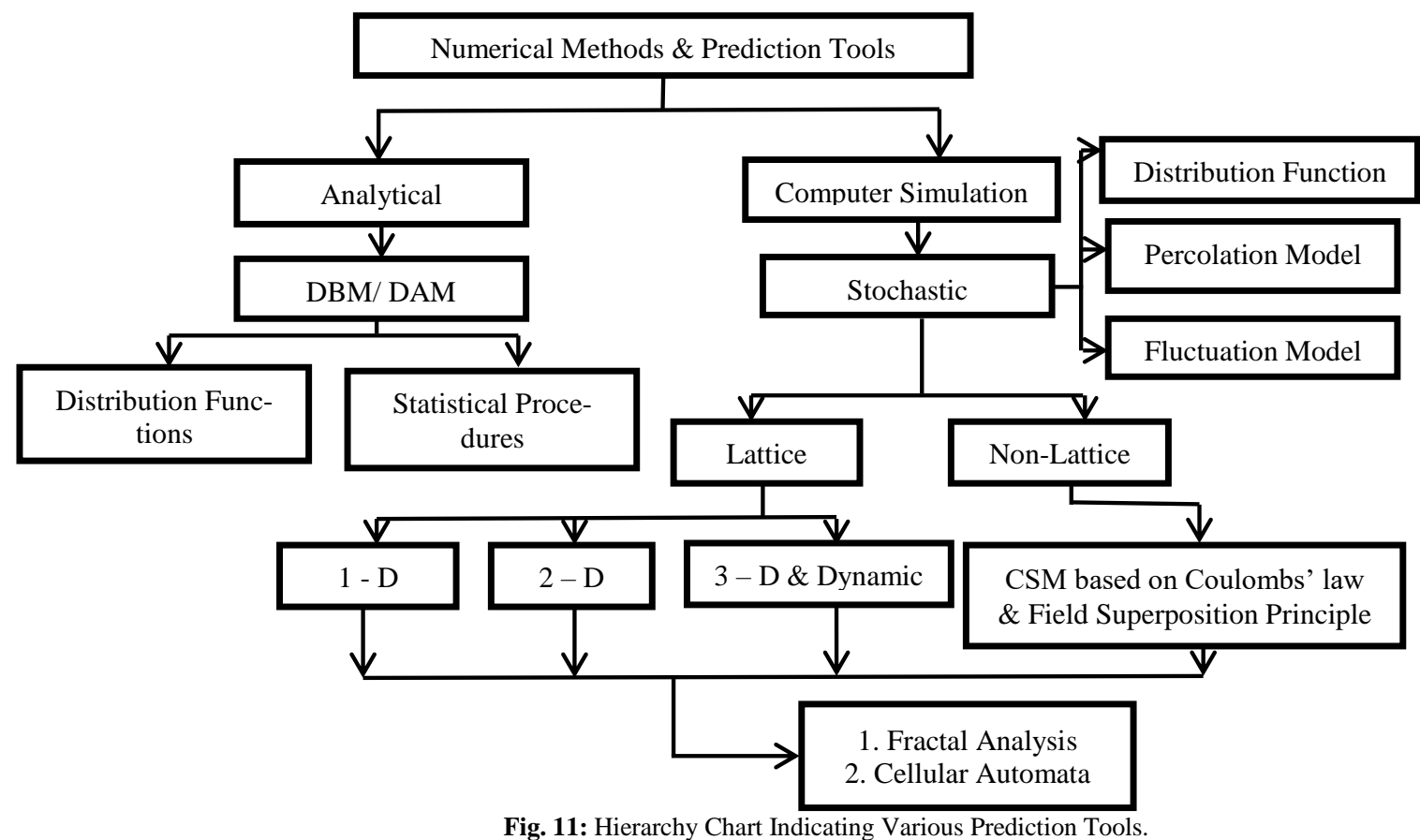

\section{Insight into prediction tools for treeing growth}

It is evident from detailed research studies that various categories of prediction tools have been proposed by researchers during the past few decades for prediction and modelling of electrical treeing in solid dielectrics. A few of the most significant tools which have been utilized by researchers include Percolation model, Fluctuation model, Fractal analysis and Cellular Automata. A detailed insight into the unique aspects of such prediction tools is deliberated to enable comprehensive understanding of the salient features of such techniques.

\subsection{Fractal analysis}

A simple yet effective stochastic model that augurs well for the study of the phenomenon of dielectric breakdown includes the fractal representation and structure. Research studies as indicated in [9], [16], [40] - [41] etc. clearly reveal the use of fractal analysis procedure for modelling the structure of electrical tree for various variations in physical conditions. The basic assumption that is made while using fractal analysis is that the growth probability of electrical tree must always depend on the intensity of local electric field. Even the exact structure of the electrical tree may be defined by the fractal dimensions as either a branch tree or a bush tree. Hence, it is evident that there is a strong likelihood that the fractal dimension and the electrical tree structure have a definite relationship with each other. Studies related to [2] reveal that the probability of tree growth and the fractal dimensions exhibit a viewpoint that establishes a contrary relationship. Hence when the value of this fractal dimension $\left(\mathrm{d}_{\mathrm{f}}\right)$ is less than 2 , it could be a branch type tree and when it lies in between the value of 2 to 3 , it could result into a bush type tree. The graphical and diagrammatic representation is described in [16] and [42] for deriving the relationship between the fractal dimension and the electrical tree structure. In addition, it is also evident that higher the rate of tree propagation the lower is the fractal dimension in solid dielectrics. There are several methods indicated in research literature for estimating the fractal dimensions as indicated in [41]. The various categories for estimation of fractal dimensions include:

- Changing coarse-graining level

- Measures based on Fractal relationship

- Correlation function

\section{- Distribution function}

- Power spectrum

Fractal measure relationship comprises utilizing several estimating methods such as mass-radius relation, sand-box method, radius of gyration, tip radius method etc. In the case of correlation function, the value of correlation function is being derived based on the density function that is related with the mass that is occupied by the entire tree structure. In using the distribution function, generally the probability density function is used for the calculations of fractal dimensions. On similar lines in using power spectrum, estimation of fractal dimensions can be obtained by the power spectrum which can be obtained by transforming the variation of spatial or temporal random process into an equivalent electric signal.

\subsection{Cellular automata (CA)}

Initially, Von-Neumann introduced Cellular automata (CA) for solving various aspects of physical systems that has an involvement of local interactions in its solution. Primarily, this form of CA is directly considered to be the physical system models in which it has a distinct space and time aspects and only the local interactions are considered. Some of the unique merits of this technique include fast computation and stable numerical inference mechanism. CA model [7] in general comprises of $n$-dimensional lattice of regular and uniform structure. The overall state of CA is considered as a physical quantity of the cell whereby eventually the value of this physical quantity at each and every cell is treated as the local state of that particular individual cell. Each of the cells is constrained only to a confined neighbourhood interaction. As a result of this it is found that the particular individual cell is considered to be incapable for global communication. If a particular cell in a lattice has designated as $(a, b)$ then with respect to Fig. 12, the CA local rule is such that,

$\mathrm{C}^{\mathrm{t}+1}{ }_{\mathrm{a}, \mathrm{b}}=\mathrm{F}\left[\mathrm{C}_{(\mathrm{a}-1, \mathrm{~b}-1)}^{\mathrm{t}}, \mathrm{C}_{(\mathrm{a}-1, \mathrm{~b})}^{\mathrm{t}}, \mathrm{C}_{(\mathrm{a}-1, \mathrm{~b}+1)}^{\mathrm{t}}, \mathrm{C}_{(\mathrm{a}, \mathrm{b}-1)}^{\mathrm{t}}, \mathrm{C}_{(\mathrm{a}, \mathrm{b})}^{\mathrm{t}}\right.$,

$\left.\mathrm{C}_{(a, b+1)}^{\mathrm{t}}, \mathrm{C}_{(\mathrm{a}+1, \mathrm{~b}-1)}^{\mathrm{t}}, \mathrm{C}_{(\mathrm{a}+1, \mathrm{~b})}, \mathrm{C}^{\mathrm{t}}(\mathrm{a}+1, \mathrm{~b}+1)\right]$

Where $\mathrm{C}_{\mathrm{a}, \mathrm{b}}^{\mathrm{b}}$ and $\mathrm{C}^{\mathrm{t}+1}{ }_{\mathrm{a}, \mathrm{b}}$ denotes the present states of cell $(\mathrm{a}, \mathrm{b})$ in the lattice at time steps $t$ and $t+1$ respectively.

\begin{tabular}{|l|l|l|l|l|}
\hline & & & & \\
\hline & $(\mathrm{a}-1, \mathrm{~b}-1)$ & $(\mathrm{a}-1, \mathrm{~b})$ & $(\mathrm{a}-1, \mathrm{~b}+1)$ & \\
\hline & $(\mathrm{a}, \mathrm{b}-1)$ & $(\mathrm{a}, \mathrm{b})$ & $(\mathrm{a}, \mathrm{b}+1)$ & \\
\hline & $(\mathrm{a}+1, \mathrm{~b}-1)$ & $(\mathrm{a}+1, \mathrm{~b})$ & $(\mathrm{a}+1, \mathrm{~b}+1)$ & \\
\hline & & & & \\
\hline
\end{tabular}

Fig. 12: N-Dimensional Array of Cellular Automata. 
Table 5 shows the local rule applied to all the cells that are present in a CA grid.

Table 5: Common Local Rule Applied to All Cells in Cellular Automata

\begin{tabular}{llll}
\hline CA property & Time step & Conditions \\
\hline \multirow{3}{*}{$\begin{array}{l}\text { State of the (a,b) } \\
\text { cell }\end{array}$} & 1 & 1 & Already a part of tree \\
& 0 & 0 & $\begin{array}{l}\text { None of its neighbor's state is 1 } \\
\text { One or more of its neighbor's state } \\
\text { are 1 }\end{array}$ \\
\hline
\end{tabular}

The algorithmic flow to describe this CA model can be explained here as a step by step procedure:

Step 1: Bifurcate the total volume available on the dielectric into $\mathrm{m}$ $\times \mathrm{n}$ square matrix with individual cells.

Step 2: Use the Laplace equation to find out the initial value of the electric field at time $\mathrm{t}=0$ in the point at a particular cell where the needle tip present.

Step 3: Consider the time step at the initial stage as $\mathrm{t}=1$.

Step 4: Compute the value of electric field at all the neighbourhood cells of an array at this time step $t$ by the use of CA local rule.

Step 5: Approximately fix the total number of time steps $\left(t_{s}\right)$ in order to complete the treeing process.

Step 6: At the end of each step compare the present value of $t$ with the value of $t_{s}$.

Step 7: If the value of $t$ is less than $t_{s}$, then consider the new time step as $t$ and then proceed with computation of electric field at all the neighbourhood cells of an array as in Step 4.
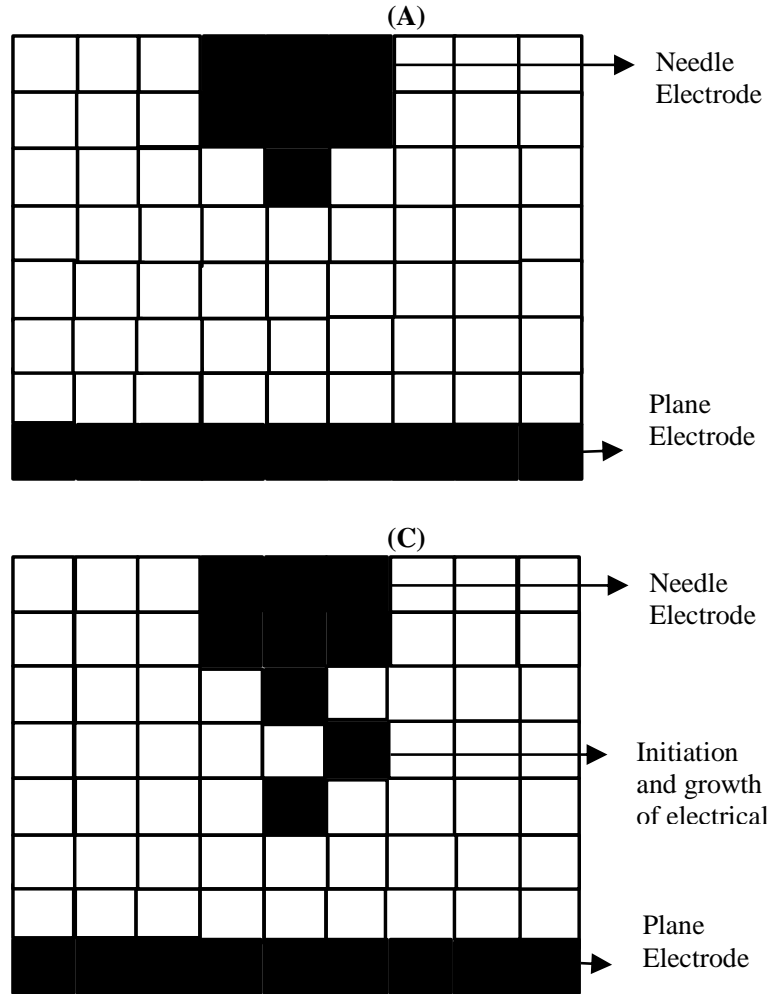

Step 8: Otherwise (i.e. the value of $t$ is greater than $t_{\mathrm{s}}$ ) complete the computation and check the potential distribution values at each and every time step as it grows like a tree.

Generally, CA are described by four different characteristics. They are:

- $\quad$ Spatial dimensions (either of 1-D, 2-D or 3-D) (n)

- Width of the side of lattice (w)

- Width of neighborhood cell (d) and

- CA local rule

In general for computation of the state $\mathrm{C}_{\mathrm{a}, \mathrm{b}}^{\mathrm{t}}$ of the cell $(\mathrm{a}, \mathrm{b})$ at time step $\mathrm{t}$ is given by [43],

$C_{a, b}^{t}=\left\{E F_{a, b}, T F_{a, b}, \epsilon_{a, b}, V_{a, b}^{t}\right\}$

Where $\mathrm{EF}_{\mathrm{a}, \mathrm{b}}$ represents the Electrode flag $(\mathrm{EF})$ which indicates whether the cell belongs to the electrodes or to the dielectric, $\mathrm{TF}_{\mathrm{a}, \mathrm{b}}$ refers to the Tree Flag (TF) which represents whether the cell belongs to tree structure or not, $\varepsilon_{\mathrm{a}, \mathrm{b}}$ denotes the local permittivity is the mean value of randomly distributed permittivities in $(a, b)$ cell and $\mathrm{V}_{\mathrm{a}, \mathrm{b}}$ represents the potential at the center of the $(\mathrm{a}, \mathrm{b})$ cell at time t. Fig. 13 indicates a typical case of step-by-step development of the conducting channel as electrical tree with the aid of CA model applied in solid insulating material.

(B)

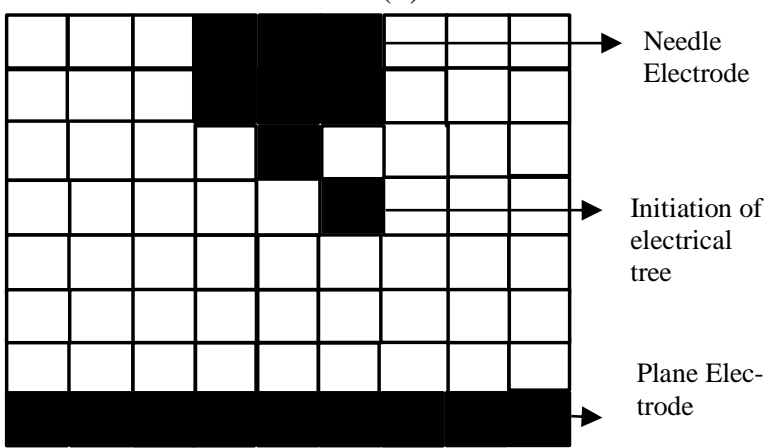

(D)

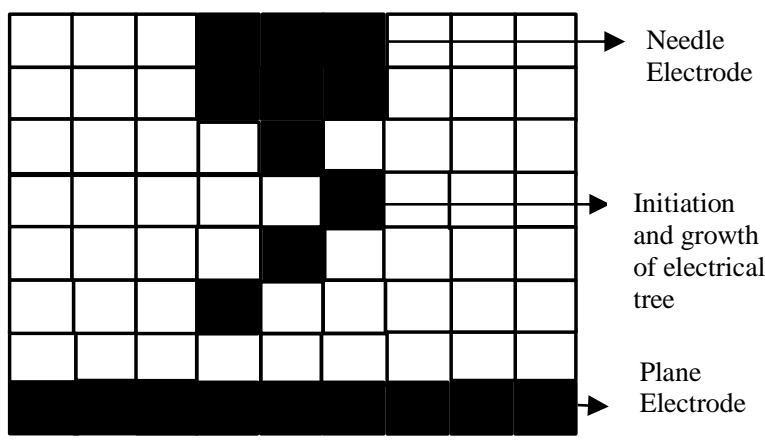

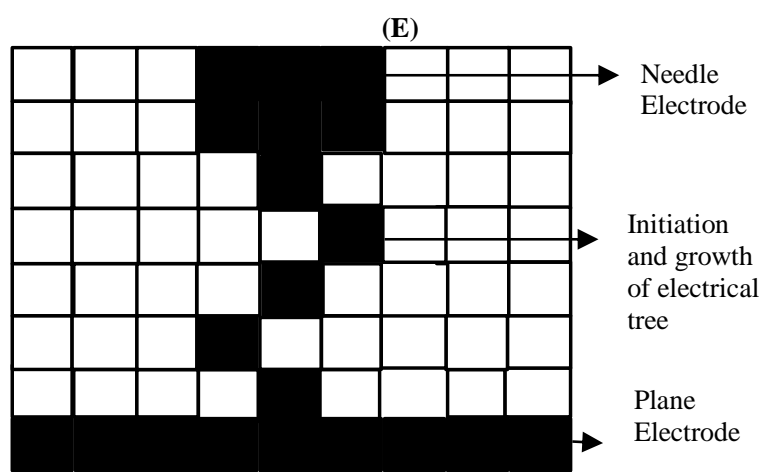

Fig. 13: (A) Typical Arrangement of CA Cells with Needle-Plane Electrode, (B) - (E) Electrical Tree Initiation and Step-by-Step Growth Towards the Opposite Electrode 
Recently the concept of CA has been effectively utilized by various researchers like [5]-[6], [11], [43]-[46] for their investigations related to the growth characteristics of electrical trees with distinct features of inclusion of dielectric inhomogeneity factor, effect of space charge, nano-composites etc. especially in case of solid dielectrics which are as specified in Table 6 .

Table 6: Literature Review of Cellular Automata

\begin{tabular}{|c|c|c|c|}
\hline $\begin{array}{l}\text { Researcher \& } \\
\text { Year }\end{array}$ & $\begin{array}{l}\text { Distinct Feature } \\
\text { used for } \\
\text { analysis }\end{array}$ & Specifications & Description \\
\hline $\begin{array}{l}\text { M.G. Danikas } \\
\text { et. al. [7], } \\
1996\end{array}$ & $\begin{array}{l}\text { Presence of } \\
\text { spherical void }\end{array}$ & $\begin{array}{l}\text { Applied Voltage }=20 \mathrm{kV} ; \\
\text { Distance between the tip to } \\
\text { plane }=5 \mathrm{~mm} ; \text { dielectric } \\
\text { constant }=2.1 \text { to } 2.25\end{array}$ & $\begin{array}{l}\text { 1. Algorithm is fast and numerically stable } \\
\text { 2. Assumptions made include: } \\
\text { Electric field at the end of the tip is comparable to that developed at } \\
\text { the end of the point electrode } \\
\text { The insulating material is inherently inhomogeneous } \\
\text { The tree will progress taking into account the local dielectric strength } \\
\text { 1. Maximum electric stress } \mathrm{E}_{\max } \text { at the tip of point electrode is } \boldsymbol{E}_{m a x}=\end{array}$ \\
\hline $\begin{array}{l}\text { I. Karafyllidis } \\
\text { et. al. [43], } \\
1998\end{array}$ & $\begin{array}{l}\text { Permittivity } \\
\text { variation }\end{array}$ & $\begin{array}{l}\text { Applied Voltage }=20 \mathrm{kV} \text {; } \\
\text { Distance between the tip to } \\
\text { plane }=5 \mathrm{~mm} \text {; Permittivity }= \\
2.05 \text { to } 2.30\end{array}$ & $\begin{array}{l}\frac{2 s E_{\text {avg }}}{r\left(\ln \left(1+\frac{4 s}{r}\right)\right)} \text { where } \mathrm{s} \text { is the electrode gap spacing, } \mathrm{r} \text { represents radius of the tip of } \\
\text { point electrode, } \mathrm{E}_{\text {avg }} \text { denotes average electric stress applied to the gap spacing } \\
\text { 2. Increase in range of permittivity variation causes electrical tree to more } \\
\text { extensive and consists of more branches }\end{array}$ \\
\hline $\begin{array}{l}\text { G.E. Vardakis } \\
\text { et. al. [6], } \\
2002\end{array}$ & $\begin{array}{l}\text { Space charge } \\
\text { effect }\end{array}$ & $\begin{array}{l}50 \times 50 \text { CA cells; Applied } \\
\text { voltage }=90 \mathrm{kV} ; \text { dielectric } \\
\text { constant }=2.2 \text { to } 2.4 ; \text { Space } \\
\text { charge density }=(0-300) \\
\mathrm{Cb} / \mathrm{m}^{3}\end{array}$ & $\begin{array}{l}\text { 1. Space charges enhance the potential values, especially in the middle region of } \\
\text { the material } \\
2 \text {. The existence of space charge leads to fewer tree branches whereas without } \\
\text { space charges, more branches can appear in dielectric. } \\
\text { 3. Step-by-step movement of dendrite is considered by combination of, } \\
\text { external field created by applied voltage } \\
\text { channel local field produced by charge accumulation in the interior of the }\end{array}$ \\
\hline $\begin{array}{l}\text { George E. } \\
\text { Vardakis et. } \\
\text { al. [5], } 2004\end{array}$ & $\begin{array}{l}\text { Different } \\
\text { permittivity of } \\
\text { the material }\end{array}$ & $\begin{array}{l}500 \times 500 \mathrm{CA} \text { cells; Applied } \\
\text { voltage }=+80 \mathrm{kV},+45 \mathrm{kV} \\
+30 \mathrm{kV} \text {; Dielectric } \\
\text { inhomogeneity factor }(\mathrm{DIF})= \\
0.85 \text { to } 1.15 ; \text { relative } \\
\text { permittivity }=2.3 \& 8\end{array}$ & $\begin{array}{l}\text { 1. Uses Dirichlet and Neumann boundary conditions for potential distribution } \\
\text { calculations } \\
\text { 2. The position of particle and potential values at the circumference of the } \\
\text { particle are the crucial factors for its electrical behavior }\end{array}$ \\
\hline $\begin{array}{l}\text { G.E. Vardakis } \\
\text { et. al. [8], } \\
2005\end{array}$ & $\begin{array}{l}\text { Conducting } \\
\text { particle } \\
\text { included in } \\
\text { dielectric }\end{array}$ & $\begin{array}{l}500 \times 500 \mathrm{CA} \text { cells; Applied } \\
\text { voltage }=+40 \mathrm{kV} ; \mathrm{DIF}=0.85 \\
\text { to } 1.15\end{array}$ & $\begin{array}{l}\text { 1. Uses Dirichlet and Neumann boundary conditions for potential distribution } \\
\text { calculations } \\
\text { 2. Compares the results between the absence and presence of space charge. } \\
\text { Absence of space charge: many branches (bush-like dendrite) appear } \\
\text { near the needle tip and two main branches with few sub-branches (branch tree) } \\
\text { near the conducting particle } \\
\text { Presence of space charge: creates different tree structure at the tip of } \\
\text { the needle and no tree near the conducting particles since the space charge } \\
\text { reduces the electric field }\end{array}$ \\
\hline $\begin{array}{l}\text { Despoina } \\
\text { Pitsa et. al. } \\
\text { [47], } 2010\end{array}$ & Nano-fillers & $\begin{array}{l}5000 \times 5000 \mathrm{CA} \text { cells; } \\
\text { Applied voltage }=20 \mathrm{kV} ; \text { dif } \\
=0.9 \text { to } 1.1 ; \text { Space charge } \\
\text { density }=20 \mathrm{Cb} / \mathrm{m}^{3}\end{array}$ & $\begin{array}{l}\text { 1. Uses Neumann and Dirichlet boundary conditions for potential distribution } \\
\text { calculations } \\
\text { 2. Nano-fillers act like barriers and seem to prevent the propagation of electrical } \\
\text { trees. }\end{array}$ \\
\hline $\begin{array}{l}\text { V.A. Kioussis } \\
\text { et. al. [11], } \\
2014\end{array}$ & $\begin{array}{l}\text { Composite } \\
\text { insulating } \\
\text { system }\end{array}$ & $\begin{array}{l}60 \times 60,100 \times 100 \mathrm{CA} \text { cells; } \\
\text { Applied voltage }=35 \mathrm{kV} \\
28 \mathrm{kV}, 27 \mathrm{kV} ; \text { DIF }=0.9 \text { to } 1.1\end{array}$ & $\begin{array}{l}\text { 1. Uses Neumann and Dirichlet boundary conditions for potential distribution } \\
\text { calculations } \\
2 \text {. The phenomenon of treeing propagates through the weaker medium and not } \\
\text { through the barriers. }\end{array}$ \\
\hline $\begin{array}{l}\text { M. Hariharan } \\
\text { et. al. [40], } \\
2016\end{array}$ & $\begin{array}{l}\text { Stochastic } \\
\text { modelling }\end{array}$ & --- & $\begin{array}{l}\text { 1. Uses Dirichlet boundary conditions for determining the boundary values of } \\
\text { grid points } \\
\text { 2. Sandbox method is used for the estimation of fractal dimensions which } \\
\text { generally varies from } 1.9241 \pm 0.1071 \text { to } 1.821 \pm 0.037\end{array}$ \\
\hline $\begin{array}{l}\text { Hemza } \\
\text { Medoukali et. } \\
\text { al. [48], } 2016\end{array}$ & $\begin{array}{l}\text { Dielectric } \\
\text { inhomogeneity } \\
\text { factor's range }\end{array}$ & $\begin{array}{l}100 \times 100 \mathrm{CA} \text { cells; Applied } \\
\text { voltage }=80 \mathrm{kV} ; \mathrm{DIF}=0.95 \\
\text { to } 1.04\end{array}$ & $\begin{array}{l}\text { 1. Uses Dirichlet and Neumann boundary conditions for potential distribution } \\
\text { calculations } \\
\text { 2. Tree stops growing if electric field is less than local dielectric strength and } \\
\text { when the dendrites reach the bottom electrode }\end{array}$ \\
\hline
\end{tabular}

\subsection{Fluctuation mode}

In general, due to the existence of certain amount of free volume in any non-crystalline materials, ions, atoms or molecules may not occupy a given lattice space continuously. Instead, it traces around and inside that of the lattice space from site to site with respect to time by maintaining the total free energy as constant. Such movements or fluctuations that might occur due to this space occupancy issues may tend to redistribute some local mechanical strain or the dipole orientations about the system. The distribution density of the particular system variable whose magnitude has been perfectly controlled by these fluctuations occurring and the resulting expression is utilized for determining the dielectric as well as the mechanical response functions. In addition, whenever this variable concerned is the local electric current then such fluctuation could give rise to the noise component with power law $\mathrm{f}^{-2(1-\mathrm{m})}$, $(0<\mathrm{m}<1)$ where the exponent $2(1-\mathrm{m})$ usually lies between the white noise (zero) to the Gaussian noise (two) as in [17].

In this model, the non-crystalline material is divided into a number of local structural units called clusters which might be composed of the structural elements like atoms, molecules etc. and might aggregate just by connecting all the motions of its structural elements to those of its neighbour or fragment by means of 'internal disconnections'. Therefore, the number of structural elements and their own configurations in any specific cluster can fluctuate in time, under the condition that the free energy could always be maintained at a constant average value for the given volume of material. Therefore, the fluctuations that is occurring may be considered as the local density fluctuations and the molecular reconfigurations 
that might occur in a non-crystalline solid due to the presence of free volume.

The probability of occurrence of any given cluster is governed by a probability density $\mathrm{g}(\mathrm{y})$ which is defined by the assumption that a given amount of energy or information content has been shared equally among all the clusters irrespective of their size and thereby restraining the free energy to be constant. Therefore, the resulting probability density is given by,

$g(y)=\frac{y^{(1-m) / m}}{m\left(y^{1 / m}+1\right)^{2}} 0 \leq m \leq 1$

Where y denotes a cluster variable (density, polarisation, space charge density etc.) scaled to its value in the characteristic cluster and $\mathrm{m}$ represents an index measuring the degree of connection between the motions in different clusters. The energy density (due to space charges, displacement field and local currents) in the characteristic cluster is made equal to the average value of applied field $\left(E_{a}\right)$, then the magnitude of electric field in the characteristic cluster can be found to be proportional to $\left(E_{a}-E_{1}\right)$. Thus,

$$
y=\frac{E}{E_{a}-E_{1}}
$$

Where $\mathrm{E}$ refers to the local field and $\mathrm{E}_{1}$ represents the RMS value of the field corresponding just to currents.

\subsection{Percolation model}

The basic physical phenomena that could relate to extending the defects by means of repetitive processes which is not likely to be deterministic but in the process it may be viewed as a stochastic process due to its inherent characteristic necessitates introducing a perfect statistical element through the probability of occurrence for different kind of defects which are identified in any solid dielectric material. However, the distribution of initial defect must have an impact on the probability that this defect might reach its critical size thereby causing a dielectric breakdown in a given time. The above considerations not only affect the rate at which a single defect grows but also the possibility of defect amalgamation during 'cluster' generation and the formation of the breakdown path. Hence, this percolation model represents the insulators by a perfect grid or lattice whose bonds are treated to be as an identical capacitor which tends to breakdown by applying a normal electric field. Incidentally, the defects are generally introduced on a random basis merely by replacing all these capacitors by ordinary conductors. Thus the initial stage of the total structure has been demarcated either by the fraction of bonds that are conducting or equivalently the volume fraction of the material that is occupied by the unit defect. This kind of construction could always lead to form a perfect percolation system of defects [17]. As a consequence, instead of isolating all the unit defects from the defect volume some of them could combine with themselves to form the conducting clusters in the defect region. Hence in this percolation model, the system breakdown could occur rapidly for the applied field $\mathrm{E}$, if the most severe (longest) cluster has a length $l_{\max }$ given by,

$1_{\max }=1_{\mathrm{c}} \propto \frac{\boldsymbol{E}_{\mathbf{0}}}{\boldsymbol{E}}$

Where $E_{0}$ denotes the field at which the breakdown occurs. Then this percolation system therefore survives if the length of that most severe (longest) cluster is less than 1 . At the same time, the cluster sizes tend to be exponentially distributed and thus the distribution density $\mathrm{g}(\mathrm{l})$ for the given length $\mathrm{l}$ is given by,

$$
g(l) \propto e^{-l / \xi}
$$

Where $\xi$ is the percolation correlation length

Table 7 clearly depicts the overall summary of the prediction tools that have been used by several researchers in the field of modelling of electrical trees in a solid insulating material.

\begin{tabular}{|c|c|c|c|}
\hline Numerical Method used & Researcher & Model / Material used & Contributions / Findings \\
\hline \multirow{4}{*}{ Fractal Analysis (FA) } & Fothergill et. al [14] & DAM & $\begin{array}{l}\text { 1. Voltage dependent time length variation is non- } \\
\text { monotonic in implanted needle which replicates by the } \\
\text { variations in fractal dimension } \\
\text { 2. Data acquired from different shapes of electrical } \\
\text { trees are handled with fractal dimensions in order to } \\
\text { get the value of total damage (S) }\end{array}$ \\
\hline & & & $\begin{array}{l}\text { 1. Geometrical patterned fractal dimensions assessed } \\
\text { accurately and three dimensionally }\end{array}$ \\
\hline & K.Kudo [41] & Stochastic model & $\begin{array}{l}\text { 2. Fractal dimensions of electrical trees are associated } \\
\text { with other sort of physical as well as chemical } \\
\text { measures }\end{array}$ \\
\hline & M. Hariharan et. al. [40] & $\begin{array}{l}\text { Stochastic model for } \mathrm{HV} \\
\text { power cables }\end{array}$ & $\begin{array}{l}\text { 1. Void existence is initiating the damage of insulating } \\
\text { material due to PD activity and affecting the level of } \\
\text { tree propagation } \\
2 \text {. From the Sand-box method of dimension estimates, } \\
\text { values that obtained for both internal and critical fields } \\
\text { varies by a small value }\end{array}$ \\
\hline \multirow{3}{*}{ Cellular Automata (CA) } & V.A. Kioussis et. al. [11] & $\begin{array}{l}\text { Epoxy resin and multiple } \\
\text { Mica sheets }\end{array}$ & $\begin{array}{l}\text { 1. Variation in field created by a factor } \mathrm{g} \text {, } \\
\text { proportionally distresses the propagation of electrical } \\
\text { tree } \\
\text { 2. An increase in applied voltage denses the thickness } \\
\text { of electrical tree }\end{array}$ \\
\hline & $\begin{array}{l}\text { Despoina Pitsa et. al. [44]- } \\
\text { [47] }\end{array}$ & $\begin{array}{l}\text { DIMET in nano-composite } \\
\text { polymers }\end{array}$ & $\begin{array}{l}\text { 1. Breakdown causing tree that initiates from HV } \\
\text { electrode has delayed to reach the counter electrode } \\
\text { due to the presence of nano-particles } \\
\text { 2. Presence of nano-particles decelerates the } \\
\text { propagation of electrical tree }\end{array}$ \\
\hline & Hemza Medoukali et. al. [48] & DIMET in XLPE sample & $\begin{array}{l}\text { 1. Effect of dielectric inhomogeneity factor }\left(\mathrm{g}_{\mathrm{dif}}\right) \text { has } \\
\text { been considered in three different cases } \\
\text { i. between } 0.95-1.04 \text {, } \\
\text { ii. between } 0.95-1 \text { and } \\
\text { iii. between } 0.97-1 \\
\text { 2. Tight range variation of } \mathrm{g}_{\text {dif }} \text { affects the shape of } \\
\text { electrical tree by thin and minimum number of } \\
\text { dendrites in it }\end{array}$ \\
\hline
\end{tabular}

Table 7: Summary on A Few of the Prediction Tools Used 


\section{Modern trends in prediction of electrical treeing degradation mechanism - state of the art}

The research studies related to initiation and propagation of electrical trees are very much alive and booming still and the works carried out by several researchers in recent years has been enhanced our understanding of the progressions considerably that contribute to the initiation and propagation of the electrical tree structures. A few of the modern trends that is utilized for the prediction of electrical treeing degradation mechanism has been discussed elaborately such as the image processing concepts, non-linear behaviour of PD pulses, properties of nano-composites etc.

\subsection{Image processing techniques}

As a state of the art technique, the modern digital image processing methods are applicable for analysing the fractal dimensions of electrical trees. In [40] one of the subordinate methods of this digital image processing is being used and called as "Image construction and image restoration models". In this approach the Sandbox method has adopted to analyze the fractal dimensions by using the statistical image processing techniques. Imaging an experimentally generated electrical tree has been considered as the significant state of the art prediction method in the research studies related to electrical treeing mechanism and in depth learning of how precisely the electrical trees are being developed in the solid insulating material.

Some of the most commonly used imaging techniques available for electrical treeing has been identified by [49] are Optical microscopy, Scanning Electron Microscopy (SEM) and Transmission Electron Microscopy (TEM) etc. By using these imaging techniques it is possible to provide only the two-dimensional (2D) features in electrical treeing and that has been considered as the limitation to those imaging techniques. But, the virtual models of electrical trees in three-dimensional (3D) features can be able to obtain by the use of X-ray Computed Tomography (XCT), Serial Block - Face SEM (SBFSEM) etc. It is worth noting from [50] that the amount of this 3D data available for research studies is limited at the same time the resolution obtained by these techniques is substantially less. Therefore, by using this $3 \mathrm{D}$ features to the available imaging techniques like XCT, SBFSEM etc. the electrical trees are characterised through the general parameters like effective diameter of the tree channels, volume of the tree, quantity of volume degraded by the creation of electric field and the other local parameters for instance number of tree branches, effective area of tree channels and the quantity of area degraded etc.

\subsection{Non-linear behaviour of PD pulses}

All the modern digital systems as in [20] available for the PD measurement has been allowing many of the quantities to be derived which are closely related with the amount of degradation that are treated as analytical quantities which gives a clear picture of PD degradation mechanism. Investigations persist aimed to understand the non-linear behaviour of time dependent PD pulses that have to be obtained from a typical electrical tree. This has been suggested by [42] and uses a section of XLPE cable insulation sample to ensure that the deterministic chaos exists in the entire PD activity during the propagation of typical electrical trees. Some form of broad band sensors is used in [51] in order to identify the level of UHF signal which has been radiating during the occurrence of PD. Hence the signal bandwidth of this UHF signal might be varied in between 0.5 to $2.0 \mathrm{GHz}$ which is helpful in identifying the perfectness of incipient discharges that occur at the time of propagation of electrical trees. By implementing the results which are being obtained from the analysis of UHF signal that is being generated in a de Finetti diagram (triangle plot), it can permit to sort the shape of the electrical tree. In recent years, [52] utilizes a Phase Resolved Partial Discharge Analyzer (PRPDA) to acquire the patterns of PD during the tests conducted on electrical treeing for the determination of the tree inception voltage with the presence of this nano-composite. In addition to that [53] - [54] gives a better idea for analysing the partial discharges as a prognostic indicator by utilizing the technique called Phase resolved partial discharge analysis (PRPDA) in combination with the Pulse sequence analysis (PSA) out of which it has been concluded that the component PSA can be measured with greater prognostic suitability index than PRPDA that depends on the effective sum of three different features of monotonicity, prognosability and trendability. From these discussions it is being concluded that it is possible to predict the effect of insulation failure earlier than the actual breakdown of insulation that occurs completely.

\subsection{Properties of nano-composites}

In [45], the characteristics of electrical treeing have been studied in nano-composite materials with the presence of impurities and it has concluded that the presence of impurities provokes degradation of the dielectric. In addition to this, the degree of degradation is affected by the number of impurities present. In addition, [44] proposed the relative permittivity model for electrical treeing with reference to some of the other interesting models such as Lewis model, Tsagaropoulos' model, multi-core model, interphase volume model, potential barrier model and polymer chain alignment model which gives an idea of interfacing arrangement and the properties that exhibits by the nano-composite dielectrics. Accordingly, the interface relative permittivity $\left(\varepsilon_{\mathrm{x}}\right)$ may be calculated by the following exponential formula:

$\varepsilon_{(x)}=\left\{\begin{array}{c}\varepsilon_{n}, x<r \\ \varepsilon_{n} \cdot \exp \left[-k \cdot(x-r)^{2}\right], r \leq x \leq r+l \\ \varepsilon_{p}, x>r+l\end{array}\right\}$

Where $\varepsilon_{\boldsymbol{n}}$ is the nano-particles relative permittivity, $\varepsilon_{\boldsymbol{p}}$ denotes the relative permittivity of polymer, $\mathrm{k}$ indicates attenuation coefficient, $\mathrm{x}$ represents distance from nano-particle center, $\mathrm{r}$ is the radius of nano-particle and 1 denotes interface thickness.

In Lewis model [55], the important scaling factor for conduction in nano-composite is the cross-section of the conducting particles present in the dielectric and it is thereby proved that the combination of the nano-composite particle and the dielectric can act as a distributed electron-hole recombination centers. Tsagaropoulos' model [56] mainly deals with the interaction of dielectric with the silica particles of high surface area. It is concluded by this model that, the silica particle restricts the mobility of the tree channel and thus leads to the establishment of new glass transition. The multi-core model proposed by [57] deals with the several properties that could have been exhibit by the nanocomposites as a dielectric. Majorly, the interface between nanocomposite and dielectric can be analysed by electro-chemical properties. In general, in a multi-core model a spherical filler material is considered with four different layers such as a bonded layer, a bound layer, a loose layer and an electric double layer which overlaps all the above three layers which is called as GouyChapman layer. Out of these four layers the first two layers are responsible for PD resistance, while the third layer may not play a role on this PD resistance.

\section{Future challenges and prospective tech- niques}

This review provides unique aspects from the perspective of prediction assessment during treeing studies and the following salient aspects may be considered as important aspects that would 
be treated as future challenges that are put forth for the researchers. Also some of the prospective techniques that might also be expected to justify by the researchers worldwide in the field of modelling of electrical treeing initiation and propagation in the solid insulation systems.

- The process involving in breaking chemical bonds in solid insulation and the involvement of UV assisted chain scission are still unknown.

- Effect of the field that have been enhanced very close to the final edge of the electrical tree.

- The response of the electrodes whenever there is a change in applied voltage exists immediately after the initiation of treeing process.

- The relationship between the number / size of the voids that are present inside the dielectric and the time taken for the breakdown

- During explore possibility of utilizing digital image processing techniques to understand and analyze treeing and breakdown mechanism in nano- dielectrics.

- In a less conducting electrical trees, the assumption / effect of the non-conducting gases that are produced during the treeing process may also take into consideration.

\section{Conclusions}

This research review presents a holistic overview of various electrical treeing aspects, characteristics, modelling and state of the art prediction studies carried out thus far by researchers worldwide. It is evident from the discussions that though several deterministic as well as stochastic modelling techniques have been conceived and implemented to simulate and replicate electrical treeing initiation, propagation and growth substantial challenges continue to confront the research community in specific aspects. The following complexities related to real-time analysis of treeing phenomenon are summarized:

1) From the perspective of field theoretic modelling several gaps related to representation of physical degradation mechanisms such as space charge effect, dielectric inhomogeneity aspects, insulating barrier effects and its role etc. needs to be convincingly established with appropriate validation studies and analysis.

2) Due to technological advances and enhanced manufacturing capabilities, through it has become easier to utilize newer and more reliable material as dielectric / insulation systems, it is pertinent to note that for aspects related to such technologies (nano-dielectrics) which involve nano-fillers with solid dielectric suitably modified and viable strategies that would describe this composite dielectric model is comprehensively developed that establish the electrical treeing initiation and growth.

3) From the viewpoint of prediction mechanisms / techniques, though considerable studies have been made by the research community worldwide, there is a pressing need for accurate models for electrical treeing growth. Such strategies may include techniques such as 3D Cellular automata, Dynamic cellular automata, 3D imagery and prediction methods, X-ray tomography etc. Such techniques would most likely ensure better and more accurate prediction of electrical treeing initiation and growth models which could mimic real-time complexities.

\section{Acknowledgement}

The authors are grateful for the support and motivation by Dr. P. Arulmozhivarman, Dean / School of Electrical Engineering (SELECT), Vellore Institute of Technology during the course of this research study.

\section{References}

[1] Yuzo Takashi, "Two hundred years of Lichtenberg figures", Journal of Electrostatics, Vol. 6, No.1, (1979), pp. 1-13 https://doi.org/10.1016/0304-3886(79)90020-2.

[2] Sarathi R., AnilKumar CR, Venkataseshaiah C \& Jayaganthan R, "Influence of homo- and heterocharges on the growth dynamics of electrical trees", Materials letters, Vol. 58, (2004), pp. 2386-2392. https://doi.org/10.1016/j.matlet.2004.02.013.

[3] Venkatesh S, Mohamed Ghouse S, Ramamoorthi PV \& Natarajan S, "Role of Insulating barriers during Electrical treeing in Composite Dielectrics using Partial discharge signature analysis based on Adaptive Probabilistic Neural network", IEEE International Conference on Condition monitoring and Diagnosis, Indonesia, (2012), pp. 1063-1066.

[4] Dissado LA "Understanding Electrical Trees in Solids: From Experiment to Theory", IEEE Transactions on Dielectrics and Electrical Insulation, Vol. 9, No.4, (2002), pp. 483-497. https://doi.org/10.1109/TDEI.2002.1024425.

[5] Vardakis GE, \& Danikas MG, "Simulation of electrical tree propagation in a solid insulating material containing spherical insulating particle of a different permittivity with the aid of Cellular Automata", Facta universitatis-series: Electronics and Energetics, Vol. 17, (2004), pp. 377-389. https://doi.org/10.2298/FUEE0403377V.

[6] Vardakis GE, Danikas MG \& Karafyllidis I, "Simulation of spacecharge effects in electrical tree propagation using Cellular Automata", Materials letters, Vol. 56, No. 4, (2002), pp. 404-409. https://doi.org/10.1016/S0167-577X(02)00512-8.

[7] Danikas MG, Karafyllidis I, Thanailakis A \& Bruning AM, "A model for electrical tree growth in solid insulating materials using Cellular Automata", IEEE international symposium on Electrical insulation, Vol. 2, (1996), pp. 887-890. https://doi.org/10.1109/ELINSL.1996.549484.

[8] Vardakis GE \& Danikas MG, "Simulation of electrical tree propagation using Cellular Automata: the case of conducting particle included in a dielectric in point-plane electrode arrangement" Journal of Electrostatics, Vol. 63, No. 2, (2005), pp. 129-142. https://doi.org/10.1016/j.elstat.2004.06.008.

[9] Sarathi R, "Dynamical aspects of electrical trees", Materials letters, Vol. 32, (1997), pp. 351-354. https://doi.org/10.1016/S0167577X(97)00058-X.

[10] Rouha N, Bercual A \& Brosseau C, "Modeling the Treeing growth in solid Electrical insulations", IEEE Conference on Electrical insulation and Dielectric phenomena, Vol. 2, (1996), pp. 750-753. https://doi.org/10.1109/CEIDP.1996.564607.

[11] Kioussis VA, Danikas MG, Christantoni DD, Vardakis GE \& Bairaktari A, "Electrical trees in a Composite insulating system consisted of Epoxy resin and mica: The case of Multiple mica sheets for machine insulation", Engineering, Technology \& Applied Science Research, Vol. 4, No.4, (2014), pp. 662-668.

[12] Elan Seralathan K, Mahajan A \& Nandini Gupta, "Modelling of Electric Tree Progression due to Space Charge Modified fields", Journal of Physics D: Applied Physics, Vol. 41, No. 10, (2008), p 105501. https://doi.org/10.1088/0022-3727/41/10/105501.

[13] Ying Liu \& Xiaolong Cao, "Electrical tree growth characteristics in XLPE cable insulation under DC voltage conditions", IEEE Transactions on Dielectrics and Electrical insulation, Vol. 22, No. 6, (2015), pp. 3676-3684. https://doi.org/10.1109/TDEI.2015.005222.

[14] Fothergill JC, Dissado LA \& Sweeney PJJ, “A Discharge-Avalanche theory for the propagation of Electrical Trees A physical basis for their voltage dependence", IEEE Transactions on Dielectrics and Electrical Insulation, Vol. 1 No. 3, (1994), pp. 474-486. https://doi.org/10.1109/94.300291.

[15] Ding HZ \& Varlow BR, "Thermodynamic Model for Electrical Tree Propagation Kinetics in Combined Electrical and Mechanical Stresses", IEEE Transactions on Dielectrics and Electrical Insulation, Vol. 12, No. 1, (2005), pp. 81-89. https://doi.org/10.1109/TDEI.2005.1394018.

[16] Xiaoquan Z, \& George Chen, "Propagation Mechanism of Electrical Tree in XLPE Cable Insulation by investigating a Double Electrical Tree Structure", IEEE Transactions on Dielectrics and Electrical insulation, Vol. 15, No.3, (2008), pp. 800-807. https://doi.org/10.1109/TDEI.2008.4543118.

[17] L.A. Dissado and J.C. Fothergill, "Electrical Degradation and Breakdown in Polymers", IET, Vol. 9, (1992). https://doi.org/10.1049/PBED009E. 
[18] Shinya Iwata "Influence of humidity treatment on electrical tree propagation in epoxy resin", IEEE Transactions on Dielectrics and Electrical Insulation, Vol. 23, No. 5, (2016), pp. 2556-2561. https://doi.org/10.1109/TDEI.2016.7736812.

[19] Dodd SJ, Chalashkanov NM \& Fothergill JC, "Partial discharge patterns in conducting and non-conducting electrical trees", 10th IEEE International Conference on Solid Dielectrics, (2010), pp. 1-4 https://doi.org/10.1109/ICSD.2010.5568217.

[20] Montanari GC, Mazzanti G \& Simoni L, "Progress in Electrothermal life modeling of electrical insulation during the last decades", IEEE Transactions on Dielectrics and Electrical Insulation, Vol. 9, No. 5 , (2002), pp. 730-745. https://doi.org/10.1109/TDEI.2002.1038660.

[21] Irurzun IM, Bergero P, Mola V, Cordero MC, Vicente JL \& Mola EE, "Dielectric breakdown in solids modeled by DBM and DLA", Chaos, Solitons \& Fractals, Vol. 13, No. 6, (2002), pp. 1333-1343. https://doi.org/10.1016/S0960-0779(01)00142-4.

[22] Niemeyer L, Pietronero L, \& Wiesmann HJ, "Fractal dimension of dielectric breakdown", Physical Review Letters, Vol. 52, No. 12, (1984), pp.

$1033-1036$ https://doi.org/10.1103/PhysRevLett.52.1033.

[23] Nyanteh Y, Graber L, Edrington C, Srivastava S \& Cartes D, "Overview of simulation models for partial discharge and electrical treeing to determine feasibility for estimation of remaining life of machine insulation systems", Electrical Insulation Conference, (2011), pp. 327-332. https://doi.org/10.1109/EIC.2011.5996172.

[24] Noskov MD, Malinovski AS, Sack M \& Schwab AJ, "Self-consistent modeling of electrical tree propagation and PD activity", IEEE Transactions on Dielectrics and Electrical Insulation, Vol. 7, No. 6, (2000), pp. 725-733. https://doi.org/10.1109/94.891982.

[25] Noskov MD, Kukhta VR \& Lopatin VV, "Simulation of the electrical discharge development in inhomogeneous insulators", Journal of Physics D: Applied Physics, Vol. 28, No. 6, (1995), pp. 1187-1194. https://doi.org/10.1088/0022-3727/28/6/024.

[26] Pietronero L, \& Wiesmann HJ, "From physical dielectric breakdown to the stochastic fractal model", Z Physics B - Condensed Matter, Vol. 70, No. 1, (1988), pp. 87-93. https://doi.org/10.1007/BF01320543.

[27] Champion JV, Dodd SJ, \& Stevens GC, "Analysis and modelling of electrical tree growth in synthetic resins over a wide range of stressing voltage", Journal of Physics D: Applied Physics, Vol. 27, No. 5, (1994), p. 1020. https://doi.org/10.1088/0022-3727/27/5/021.

[28] Ahmad MH, Bashir N, Ahmad H, Abd Jamil AA \& Suleiman AA "An overview of electrical tree growth in solid insulating material with emphasis of influencing factors, mathematical models and tree suppression", Indonesian Journal of Electrical Engineering and Computer Science, Vol. 12, No. 8, (2014), pp. 5827-5846. https://doi.org/10.11591/telkomnika.v12i8.5556.

[29] Suzuoki Y, \& Mizutani T, "Model for electrical treeing discharges and computer simulation", Proceedings of the 6th International Conference on Properties and Applications of Dielectric Materials, vol. 1, (2000), pp. 260-263.

[30] Noskov MD, Sack M, Malinovski AS \& Schwab AJ, "Measurement and simulation of electrical tree growth and partial discharge activity in epoxy resin", Journal of Physics D: Applied Physics, Vol. 34, No. 9, (2001), p.1389. https://doi.org/10.1088/0022-3727/34/9/316.

[31] Hu HM, Yang Y, Lu W \& Zhao GP, "Electrical Tree Simulation Based on the Self-Organization Criticality", Energy and Power Engineering 5, No. 04, (2013), p. 1273. https://doi.org/10.4236/epe.2013.54B241

[32] Dodd SJ, Chalashkanov NM \& Fothergill J, "Statistical analysis of partial discharges from electrical trees grown in a flexible epoxy resin" Annual Report Conference on Electrical Insulation and Dielectric Phenomena, (2008), pp. 666-669. https://doi.org/10.1109/CEIDP.2008.4772838.

[33] El-Zein A, Talaat M \& El Bahy MM, "A numerical model of electrical tree growth in solid insulation", IEEE Transactions on Dielectrics and Electrical Insulation, Vol. 16, No. 6, (2009), PP. 1724-1734.

[34] El-Zein A, Talaat M \& El Bahy MM, "A new method to predict the electrical tree growth in solid insulation", 16th ISH Conference Proceedings, (2009), pp. D-15.

[35] Wintle HJ, "Space charge limited current in the needle-plane geometry", Journal of electrostatics, Vol. 19, No. 3, (1987), pp. 257-274. https://doi.org/10.1016/0304-3886(87)90096-9.

[36] Rowland SM, Roger Schurch, Michalis Pattouras \& Qi Li, "Application of FEA to image-based models of electrical trees with uniform conductivity" IEEE Transactions on Dielectrics and Electrical Insulation, Vol. 22, No. 3, (2015), pp. 1537-1546. https://doi.org/10.1109/TDEI.2015.7116349.
[37] Pandey JC \& Nandini Gupta, "Finite Element Method Based Simulation of Unipolar Space Charge Limited Conduction in Solid Dielectric".

[38] Bamji SS, Bulinski AT \& Prasad KM, "Electric field calculations with the boundary element method", IEEE Transactions on Electrical Insulation, Vol. 28, No. 3, (1993), pp. 420-424 https://doi.org/10.1109/14.236204.

[39] Deng Jun, Li Licheng, Hao Yanpeng, Chen He, Wang Jun \& Zheng Xin, "Application of a Fast Boundary Element Algorithm for Open Floating Potential Electrostatic Problem”, Vol. 3, No. 5, (2013), pp. 418-424.

[40] Hariharan M \& Sharanya Srinivas, "Stochastic Modelling of Electrical Tree Progression in Modern High Voltage Power Cables", International Journal of Computer Applications, Vol. 149, No.7, (2016), pp. 34-38.

[41] Kudo K "Fractal analysis of electrical trees", IEEE Transactions on Dielectrics and Electrical Insulation, Vol. 5, No. 5, (1998), pp. 713 727. https://doi.org/10.1109/94.729694.

[42] Xiangrong Chen, Yang Xu \& Xiaolong Cao, "Nonlinear time series analysis of partial discharges in electrical trees of XLPE cable insulation samples", IEEE Transactions on Dielectrics and Electrical Insulation, Vol. 21, No. 4, (2014), pp. 1455-1461. https://doi.org/10.1109/TDEI.2014.004307.

[43] Karafyllidis I, Danikas MG, Thanailakis A \& Bruning AM, "Simulation of electrical tree growth in solid insulating materials", Electrical Engineering, Vol. 81, No. 3, (1998), pp. 183192. https://doi.org/10.1007/BF01236238

[44] Pitsa D \& Danikas MG, "Modeling relative permittivity and electrical treeing in polymer nanocomposites", IEEE International Conference on Solid Dielectrics, (2013), pp. 832-835. https://doi.org/10.1109/ICSD.2013.6619709.

[45] Pitsa D \& Danikas MG, "Electrical degradation due to treeing in nanocomposite dielectric materials with impurities", IEEE 10th International Conference on Properties and Applications of Dielectric Materials, https://doi.org/10.1109/ICPADM.2012.6318970.

[46] Pitsa D, Vardakis GE, Danikas MG \& Chen Y, "Electrical tree simulation and breakdown in nanocomposite polymers: The role of nanoparticles", 10th IEEE International Conference on Solid Dielectrics, (2010), https://doi.org/10.1109/ICSD.2010.5568242.

p. $1-3$

] Pitsa D, Vardakis G, Danikas MG \& Masahiro Kozako, "Electrical treeing propagation in nanocomposites and the role of nanofillers: simulationwith the aid of cellular automata", Journal of Electrical Engineering, Vol. 61, No. 2, (2010), pp. 125-128. https://doi.org/10.2478/v10187-010-0018-3.

[48] Medoukali Hemza, Mossadek Guibadj \& Boubaker Zegnini, "Effect of the Dielectric Inhomogeneity Factor's Range on the Electrical Tree Evolution in Solid Dielectrics", Advances in Electrical and Electronic Engineering, Vol. 14, No. 5, (2016), pp. 498-505.

[49] Schurch Roger, Rowland SM, Bradley RS \& Withers PJ, “A novel approach for imaging of electrical trees", Annual Report Conference on Electrical Insulation and Dielectric Phenomena, (2012), pp. 593 596.

[50] Schurch Roger, Rowland SM, Bradley RS \& Withers PJ, "Three dimensional characterisation of electrical trees", IEEE Conference on Electrical Insulation and Dielectric Phenomena, (2013), pp. 494 497.

[51] Sarathi R, Arya Nandini \& Danikas MG, "Understanding electrical treeing phenomena in XLPE cable insulation adopting UHF technique", Journal of Electrical Engineering, Vol. 62, No. 2 (2011), pp. 73-79. https://doi.org/10.2478/v10187-011-0012-4.

[52] Guastavino F, Della Giovanna L, Torello E, Hoyos M \& Tiemblo Magro P, "Electrical treeing characterisation of nanocomposite blends", IEEE Conference on Electrical Insulation and Dielectric Phenomena, (2015), pp. 816-819. https://doi.org/10.1109/CEIDP.2015.7352124.

[53] Aziz NH, Catterson VM, Judd MD, Rowland SM \& Bahadoorsingh $\mathrm{S}$, "Prognostic modeling for electrical treeing in solid insulation using pulse sequence analysis", IEEE Conference on Electrical Insulation and Dielectric Phenomena, (2014). https://doi.org/10.1109/CEIDP.2014.6995906.

[54] Aziz NH, Catterson VM, Rowland SM \& Bahadoorsingh S, "Analysis of partial discharge features as prognostic indicators of electrical treeing", IEEE Transactions on Dielectrics and Electrical Insulation, Vol. 24, No. 1, (2017), pp. 129-136. https://doi.org/10.1109/TDEI.2016.005957. 
[55] Lewis TJ, “A model for nano-composite polymer dielectrics under electrical stress", IEEE International Conference on Solid Dielectrics, (2007),
https://doi.org/10.1109/ICSD.2007.4290740.

[56] Tsagaropoulos G \& Eisenberg A, "Dynamic mechanical study of the factors affecting the two glass transition behavior of filled polymers. Similarities and differences with random ionomers", Macromolecules, Vol. 28, No. 18, (1995), pp. 6067-6077. https://doi.org/10.1021/ma00122a011.

[57] Tanaka T, Kozako M, Norikazu F \& Yoshimichi Ohki, "Proposal of a multi-core model for polymer nanocomposite dielectrics", IEEE transactions on dielectrics and electrical insulation, Vol. 12, No. 4, (2005), pp. 669-681. https://doi.org/10.1109/TDEI.2005.1511092. 